\title{
Lipoproteome screening of the Lyme disease agent identifies novel inhibitors of antibody-mediated complement killing
}

Michael J. Pereira ${ }^{\mathrm{a}}$, Beau Wager ${ }^{\mathrm{a}}$, Ryan J. Garrigues ${ }^{\mathrm{b}}$, Eva Gerlach ${ }^{\mathrm{c}}$, Joshua D. Quinn ${ }^{\mathrm{a}}$, Alex Dowdell $^{\mathrm{d}}$, Marcia S. Osburne ${ }^{\mathrm{a}}$, Wolfram R. Zückert ${ }^{\mathrm{d}}$, Peter Kraiczy ${ }^{\mathrm{c}}$, Brandon L. Garcia ${ }^{\mathrm{b}}$, John M. Leong ${ }^{\mathrm{a}}$

${ }^{a}$ Department of Molecular Biology and Microbiology, Tufts School of Medicine, Tufts University, Boston, Massachusetts, USA

${ }^{\mathrm{b}}$ Department of Microbiology and Immunology, Brody School of Medicine, East Carolina University, Greenville, North Carolina, USA

${ }^{\mathrm{c}}$ Institute of Medical Microbiology and Infection Control, University Hospital of Frankfurt, Goethe University Frankfurt, D-60596 Frankfurt, Germany. Electronic address: Kraiczy@em.uni-frankfurt.de.

d Department of Microbiology, Molecular Genetics, and Immunology, University of Kansas Medical Center, Kansas City, KS, USA

MP and BW contributed equally to this work

Corresponding authors: BLG, JML

\section{Classification}

BIOLOGICAL SCIENCES: Microbiology

\section{Keywords}

Spirochete, lipoprotein, Borrelia burgdorferi, tick-borne disease, serum resistance, immune evasion, complement $\mathrm{C} 1$

\section{Author Contributions:}

- Designed research: MJP, BW, PK, BLG, JML

- Performed research: MJP, BW, RJG, PK, EG

- Contributed new reagents or analytic tools; AD, WRZ

- Analyzed data: MJP, BW, MSO, RJG, PK, BLG, JML

- Wrote the paper: MJP, MSO, JDQ, BW, RJG, BLG, JML

\section{This PDF file includes:}

\section{Main Text}

Figures 1 to 5

Tables 1 to 2 


\section{Abstract}

Spirochetal pathogens such as the causative agent of Lyme disease, Borrelia burgdorferi

37 sensu lato, encode an abundance of lipoproteins; however, due in part to their evolutionary distance from more well-studied bacteria such as Proteobacteria and Firmicutes, very few spirochetal lipoproteins have assigned functions. Indeed, B. burgdorferi devotes almost $8 \%$ of its genome to lipoprotein genes and interacts with its environment primarily through the production of at least eighty surface-exposed lipoproteins throughout its tick vector-vertebrate host lifecycle

42 (57). Several B. burgdorferi lipoproteins have been shown to serve diverse roles, such as cellular adherence or immune evasion, but the functions for most B. burgdorferi surface lipoproteins

44 remain unknown. In this study, we developed a $B$. burgdorferi lipoproteome screening platform utilizing intact spirochetes that enables the identification of previously unrecognized host interactions. As spirochetal survival in the bloodstream is essential for dissemination, we targeted our screen to $\mathrm{C}$, the first component of the classical (antibody-mediated) complement pathway. We identified two high-affinity $\mathrm{C} 1$ interactions by the paralogous lipoproteins, ErpB and ErpQ. Using biochemical, microbiological, and biophysical approaches, we demonstrated that ErpB and ErpQ inhibit the activated forms of the $\mathrm{C} 1$ proteases, $\mathrm{C} 1 \mathrm{r}$ and $\mathrm{C} 1 \mathrm{~s}$, and represent a new mechanistic class of $\mathrm{C} 1$ inhibitors that protect the spirochete from antibody-mediated

52 complement killing by allosteric regulation. In addition to identifying a novel mode of 53 complement inhibition, our study establishes a lipoproteome screening methodology as a 54 discovery platform for identifying direct host-pathogen interactions that are central to the 55 pathogenesis of spirochetes, such as the Lyme disease agent. 


\section{Significance Statement}

59 Spirochetal pathogens encode an abundance of lipoproteins that can provide a critical

60 interface with the host environment. For example, Borrelia burgdorferi, the model species for

61 spirochetal biology, must survive an enzootic life cycle defined by fluctuations between vector

62 (tick) and vertebrate host. While $B$. burgdorferi expresses over eighty surface lipoproteins-

63 many of which likely contribute to host survival - the B. burgdorferi lipoproteome is poorly

64 characterized. Here, we generated a platform to rapidly identify targets of B. burgdorferi surface

65 lipoproteins and identified two orthologs that allosterically inhibit complement C1

66 subcomponents, conferring resistance to classical complement killing. This work expands our

67 understanding of complement evasion mechanisms and points towards a discovery approach for

68 identifying host-pathogen interactions that are central to spirochete pathogenesis. 
71

72

73

74

75

76

77

78

79

80

81

82

83

84

85

86

87

88

89

90

91

92

93

\section{Introduction}

The spirochete Borrelia burgdorferi sensu lato is the etiological agent of a diverse set of symptoms collectively referred to as Lyme disease, which is estimated to infect over 476,000 people annually in the U.S (1). B. burgdorferi is transmitted to humans and other reservoir hosts_-primarily small mammals and birds_ — via the bite of a nymphal or adult-stage infected hard tick (Ixodes scapularis). Upon tick feeding, bacteria are exposed to host blood in the tick midgut and then migrate to the salivary gland to be injected into the host dermis, where they establish a local spreading skin infection reflected in a characteristic expanding rash, erythema migrans $(2,3)$. The spirochetes then disseminate via the circulatory and/or lymphatic systems to colonize other sites, such as joints, heart, nervous tissue, and distant skin (4). Spirochetes can then be acquired by other feeding ticks, including larval stage ticks (5). As transovarial spread of B. burgdorferi does not occur in ticks, this feeding step is critical for intergenerational spirochetal transmission and retention of the bacterium in the tick population.

The ability of the spirochete to spread within the vertebrate host is reflected in its ability to cause multisystemic human disease, including arthritis, carditis, neuroborreliosis, and the formation of multiple erythema migrans lesions. The interaction of the Lyme disease spirochete with the host extracellular environment promotes its dissemination and persistence and is mediated, in part, by its surface lipoproteome. Spirochetal pathogens encode an abundance of lipoproteins, some of which are located on the bacterial surface $(8,69,70)$, and in fact most of $\sim 125$ B. burgdorferi lipoproteins are surface localized $(6,58)$. Many of these lipoproteins recognize identical or related host targets and/or interact with more than one host ligand (7). For example, at least 11 B. burgdorferi lipoproteins recognize host glycosaminoglycans (8), and nearly a dozen more interact directly with components of the innate immune system known as 
94 the complement cascade $(9,10)$. Understanding the interface between the complex $B$.

95 burgdorferi surface lipoproteome and host macromolecules is fundamental to improving disease treatment and pursuing novel vaccine targets. However, due in part to their evolutionary distance

97 from the better-studied bacteria such as Proteobacteria and Firmicutes, relatively few $B$.

98

burgdorferi lipoproteins have assigned functions.

For both survival during exposure to the bloodmeal in the tick midgut and dissemination of the spirochete throughout the vertebrate host, protection against host defenses is essential. The complement system is the most immediate threat to survival that pathogens must contend with in the blood. This system is composed of a set of soluble and membrane-associated proteins that interact and activate a multistep proteolytic cascade upon detection of microbial surfaces, ultimately forming complexes that can damage microbial membrane integrity, recruit immune cells, and enhance phagocytosis (11-14). The three canonical pathways of complement system activation are each triggered by the recognition of molecular patterns on pathogenic surfaces. The lectin pathway (LP) proceeds by the recruitment of serine proteases (MASPs) to mannosebinding lectin $(\mathrm{MBL})$ bound to the microbial surface by recognition of mannose or related sugars. The alternative pathway (AP) is triggered when complement factor C3 undergoes spontaneous self-cleavage in proximity of a microbial surface; it also serves as the central amplification loop of the complement cascade. The classical pathway (CP) typically initiates through the binding of host $\mathrm{C} 1$ to $\operatorname{IgG}$ or IgM complexes on the bacterial surface, although pathogen- or damage-associated molecular patterns can also trigger this pathway. All three pathways result in the formation of enzymatic complexes that trigger the release of proinflammatory peptides, the opsonization of the microbe, and the formation of a membrane attack complex (MAC) that lyses the pathogen. 
To promote survival during tick feeding and/or spread within the vertebrate host, $B$.

118

119

120

121

122

123

124

125

126

127

128

129

130

131

132

133

134

135

136

137

138

139

burgdorferi encodes surface lipoproteins that inhibit key steps of complement activation $(9,10$,

71). B. burgdorferi OspC (Outer surface protein C), a lipoprotein essential to the spirochete life cycle, binds to $\mathrm{C} 4 \mathrm{~b}$ to inhibit $B$. burgdorferi bloodstream clearance (15). In addition, $B$.

burgdorferi produces three distinct classes of Factor $\mathrm{H}$ binding proteins termed Complement Regulator Acquiring Surface Proteins (CRASPs), including CspA (CRASP-1), CspZ (CRASP2), and ErpP/ErpC/ErpA (CRASP-3/CRASP-4/CRASP-5) (16-25). Each of these proteins binds Factor $\mathrm{H}$, the major negative host regulator of the central amplification loop of the complement cascade and protects the bacterial surface from C3 deposition (59). The timing of expression varies among CRASPs, and CspA is specifically required for tick-to-host spirochete transmission, whereas CspZ mediates dissemination through the bloodstream and into distal tissues $(26,27)$.

Among known borrelial complement evasion proteins, B. burgdorferi BBK32 is unique in its ability to bind the complement $\mathrm{C} 1$ complex $(28,29)$. As the sole activator of the $\mathrm{CP}, \mathrm{C} 1$ is comprised of the scaffold protein $\mathrm{C} 1 \mathrm{q}$ and a heterotetramer of the serine proteases $\mathrm{C} 1 \mathrm{r}$ and $\mathrm{C} 1 \mathrm{~s}$ (i.e., $\mathrm{C} 1 \mathrm{qC} 1 \mathrm{r}_{2} \mathrm{C} 1 \mathrm{~s}_{2}$ ). $\mathrm{C} 1 \mathrm{q}$ binding to the $\mathrm{Fc}$ region of an engaged antibody activates $\mathrm{C} 1 \mathrm{r}$ to cleave $\mathrm{C} 1 \mathrm{~s}$, which in turn cleaves complement components $\mathrm{C} 2$ and $\mathrm{C} 4$, leading to downstream $\mathrm{C} 3$ and $\mathrm{C} 5$ activation. BBK32 binds the $\mathrm{C} 1$ complex by recognizing $\mathrm{C} 1 \mathrm{r}$, blocking $\mathrm{C} 1 \mathrm{r}$ proteolytic activity. When ectopically produced in a non-infectious, high-passage, otherwise serum-sensitive B. burgdorferi strain, BBK32 confers serum resistance (28). However, in an infectious strain background (i.e., strain B31), a $\Delta b b k 32$ mutant remains resistant to $\mathrm{CP}$-mediated complement killing (28), suggesting that additional borrelial factors protect the spirochete from complement activation through this pathway. 

maintained during in vitro culture, thus complicating genetic approaches to the identification of novel virulence factors (30). Nevertheless, a transposon library of B. burgdorferi has previously

143 proved useful for genome-wide screens to identify many virulence factors (31). Unfortunately,

144 functional redundancy of lipoproteins may limit its utility in exploring the genome for host

145 interactions. Alternatively, gain-of-function studies have allowed researchers to detect the 146 acquisition of new virulence-associated functions, such as complement resistance or cell

147 attachment $(28,32,72,73)$. This is accomplished through ectopic lipoprotein production in a 148 high-passage strain that, due to stochastic plasmid loss, lacks many virulence-associated

149 functions and is non-infectious. To comprehensively identify B. burgdorferi lipoproteins located 150 on the outer surface of the spirochete, Dowdell et al. ectopically produced epitope-tagged versions of all 127 putative lipoproteins encoded by B. burgdorferi strain B31 in the high

152 passage strain B31-e2, finding that more than 80 are detected on the outer surface (6).

In this study, we used this library of B31-e2 clones to establish a surface lipoproteome screening methodology. Based on the serum resistance phenotype of a bbk32-deficient mutant 155 described above and the observation that the complement evasion system of Lyme disease 156 spirochetes has evolved to be functionally overlapping, we targeted our lipoproteome screen

157 towards the human $\mathrm{C} 1$ complex. We found that two members of the Erp lipoprotein family, ErpB and ErpQ, bind $\mathrm{C} 1$ with high affinity and block its activity through a mechanism involving

159 allosteric inhibition of the $\mathrm{C} 1$ s protease subcomponent. Furthermore, we show that ErpB and ErpQ promote resistance to antibody-dependent complement killing. The discovery of a new role

161 for ErpB and ErpQ in evading complement provides a validation of our lipoproteome screening 
bioRxiv preprint doi: https://doi.org/10.1101/2021.09.23.461563; this version posted September 23, 2021. The copyright holder for this preprint (which was not certified by peer review) is the author/funder. All rights reserved. No reuse allowed without permission.

162 methodology, which may be leveraged again in future studies to better understand the host-

163 pathogen interface of the most prominent vector-borne pathogen in North America.

164 


\section{Results}

\section{Screening the $B$. burgdorferi surface lipoproteome identifies high-affinity interactions}

\section{between ErpB and ErpQ with human C1}

Utilizing a previously described lipoproteome library, we developed a whole-cell binding assay to screen 80 strains of B. burgdorferi B31-e2 that each ectopically overproduce a single distinct C-terminally His-tagged, surface-localized lipoprotein from the B. burgdorferi lipoproteome (6) for the ability to adhere to candidate ligands. As non-adherent controls, we included the parental strain B31-e2, as well as a strain that overproduces the periplasmiclocalized lipoprotein BB0460. The 80 strains were previously shown to express surface-localized lipoproteins (6). To validate our approach, we first screened the library for strains that bind to human fibronectin. As expected, the two strains that bound fibronectin most strongly overexpressed the B. burgdorferi outer surface lipoproteins BBK32 and RevA, each of which have been shown to bind human fibronectin (34-38) (Fig S1, Table S1).

To identify surface lipoproteins that target the classical complement pathway (CP), we screened the library for binding to purified, immobilized, human $\mathrm{C} 1$ complex. In addition to binding fibronectin and dermatan sulfate, BBK32 binds $\mathrm{C} 1$ (28, 29), and, as expected, spirochetes overexpressing BBK32 bound specifically to $\mathrm{C} 1$ in our screen (Fig 1A, blue). Interestingly, strains overexpressing lipoproteins ErpB or ErpQ also bound strongly to C1, exhibiting a relative signal higher than that of the BBK32-expressing strain (Fig 1A).

ErpB and ErpQ are members of the B. burgdorferi OspEF-related protein family (Erps) (39-41). All erp genes are encoded on circular plasmid 32 DNA elements (cp32), and in $B$. burgdorferi strain B31, ten cp32 plasmids together encode 13 Erp proteins (39-41). Of these, five belong to the Elp subfamily of Erps, which includes ErpB and ErpQ, and is defined by 
OspE/F-like leader peptides (Elps) (42). In addition to ErpB and ErpQ, the B. burgdorferi strain B31 genome includes Elp members ErpM, ErpO, and ErpX (Table S2). Despite being encoded on separate $\operatorname{cp} 32$ plasmids, $\operatorname{erp} B$ and $\operatorname{erp} O$ are identical at the amino acid sequence level, and for simplicity, ErpO will be referred to as ErpB hereafter. In strain B31, the Elp proteins (i.e., ErpB, ErpM, ErpQ, and ErpX) are 44-59\% identical and 59-76\% similar and exhibit their highest identity in the N-terminal and C-terminal protein regions (Fig S2, Table S2).

To confirm the results of our screen, and because little is known about the function of Elp proteins, we individually tested strains producing each Elp in the ELISA-based spirochete 196 binding assay against the $\mathrm{C} 1$ complex, including bovine serum albumin (BSA) as a negative control (Fig 1A, inset). Spirochetes expressing BBK32 (a C1-binding protein) and BB0460 (a periplasmic-localized lipoprotein (6)), were used as positive and negative controls, respectively. Strains producing ErpB, ErpQ, or BBK32 all exhibited statistically significant binding to C1 relative to BSA, whereas ErpM, ErpX, and BB0460 did not (Fig 1A, inset).

To further investigate the ability of ErpB and ErpQ to directly bind to human $\mathrm{C} 1$, we purified recombinant GST-tagged fusion proteins (GST-ErpB and GST-ErpQ). Consistent with data obtained from the spirochete binding assay (Fig 1A), GST-ErpB and GST-ErpQ bound with high-affinity to immobilized $\mathrm{C} 1$ in an ELISA-type binding assay, exhibiting apparent 205 equilibrium dissociation constants $\left(K_{\mathrm{D}}\right)$ of $3.4 \mathrm{nM}$ and $3.8 \mathrm{nM}$, respectively (Fig 1B, Table 1). 206 To gain insight into the interaction of ErpB and ErpQ with soluble C1, we used surface plasmon 207 resonance (SPR) whereby GST-ErpB and GST-ErpQ were immobilized on SPR sensor chips. 208 When C1 was used as an analyte, strong C1-binding was observed, with GST-ErpB and GST- 
1). Together, these data confirm that ErpB and ErpQ individually promote spirochete binding to human $\mathrm{C} 1$ via direct interaction with this molecule.

\section{ErpB and ErpQ selectively bind the activated forms of C1r and C1s.}

The $\mathrm{C} 1$ complex is composed of $\mathrm{C} 1 \mathrm{q}$ and a heterotetramer of $\mathrm{C} 1 \mathrm{r}$ and $\mathrm{C} 1 \mathrm{~s}$ (i.e. $\left.\mathrm{C} 1 \mathrm{r}_{2} \mathrm{C} 1 \mathrm{~s}_{2}\right)$

(Fig S3A). C1q is a non-enzymatic component and functions in pattern recognition, while $\mathrm{C} 1 \mathrm{r}$ and $\mathrm{C} 1 \mathrm{~s}$ are serine proteases that catalyze the initial proteolytic reactions of the $\mathrm{CP}$. To clarify whether ErpB and ErpQ bind to $\mathrm{C} 1$ by interacting with individual subcomponents, we carried out an ELISA-type binding assay using purified immobilized $\mathrm{Clq}$ and activated forms of C1r and C1s (i.e. C1r enzyme and C1s enzyme). Relative to the negative control GST-BB0460, no significant interaction was detected for either GST-ErpB or GST-ErpQ with human C1q, (Fig S3B $)$. In contrast, each protein bound with high affinity to $\mathrm{C} 1 \mathrm{r}$ enzyme $\left(K_{\mathrm{D}}\right.$ of GST-ErpB/C1r $=$ $41 \mathrm{nM}$; GST-ErpQ/C1r $=11 \mathrm{nM})$ as well as to C1s enzyme $\left(K_{\mathrm{D}}\right.$ of GST-ErpB/C1s $=6.7 \mathrm{nM}$; GST-ErpQ/C1s = 4.7 nM) (Fig S3C, D, Table 1).

To further study the interaction of C1r and C1s with ErpB and ErpQ, we utilized Farwestern blot analysis, detecting the His tag on the ectopically produced lipoprotein. We.first assessed the apparent molecular weights of ErpB and ErpQ in bacterial lysates by conventional western blotting, Pronase treatment was used to assess the surface-localization of each protein, as previously described (6). As expected, ErpB and ErpQ were predominantly expressed on the spirochetal surface and were detected as bands migrating at $61 \mathrm{kDa}$ and $55 \mathrm{kDa}$, respectively. Full-length ErpQ was produced at higher levels than ErpB, and the presence of a prominent lower molecular weight ErpB band - presumably a stable degradation product — suggested that ErpB, but not ErpQ was subjected to proteolytic cleavage (Fig S4A-C). The higher level of ErpQ production correlated with a somewhat shorter bacterial length when observed under darkfield 
microscopy. We then probed these bacterial lysates using purified human $\mathrm{C} 1$ or the $\mathrm{C} 1$ subcomponent proteases to test for potential protein-protein interactions. Lysates from spirochetes expressing BBK32 (a C1r-binding positive control) contained a species that bound strongly to $\mathrm{C} 1$ complex, C1r proenzyme, and C1r enzyme, but, as expected, to neither form of C1s (Fig 2 A, B). In all cases the C1/C1r-binding species correlated with epitope-tagged BBK32 (Fig S4A). The negative control BB0460 lysates contained no species that bound detectably to any complement protein probe (Fig 2 A, B). Consistent with the data shown in Figs 1 and S3, single bands coincident with ErpB and ErpQ, as judged by an $\alpha-6 x H i$ blot (Fig S4A), bound to C1 complex, C1r enzyme, and C1s enzyme (Fig 2 A, B). Furthermore, this binding was reduced in the lysates of cells treated with pronase (Fig 2 A, B).

Interestingly, we found that C1r proenzyme failed to bind either ErpB or ErpQ spirochete lysates (Fig 2A). Similarly, C1s proenzyme showed lower relative binding to ErpB and ErpQ compared to the activated form of $\mathrm{C} 1 \mathrm{~s}$ (Fig 2B). To follow up on this intriguing finding, we measured the relative affinities of pro- and active forms of both $\mathrm{C} 1 \mathrm{r}$ and $\mathrm{C} 1 \mathrm{~s}$ for recombinant GST-ErpB and GST-ErpQ by SPR. Indeed, while GST-ErpB and GST-ErpQ bound to C1r enzyme with $K_{\mathrm{D}}$ values of $100 \mathrm{nM}$ and $97 \mathrm{nM}$, respectively, neither protein exhibited detectable binding for C1r proenzyme (Fig 2C, S5). Similarly, GST-ErpB and GST-ErpQ bound C1s enzyme with $\sim 70$-fold and $\sim 38$-fold higher affinity, respectively, than $\mathrm{C} 1$ s proenzyme $\left(K_{\mathrm{D}}=3.9\right.$ nM vs. $270 \mathrm{nM} ; K_{\mathrm{D}}=4.5 \mathrm{nM}$ vs. $\left.170 \mathrm{nM}\right)($ Fig 2D, S5, Table 1).

\section{ErpQ inhibits C1s cleavage of $\mathrm{C} 2$ and $\mathrm{C} 4$}

Having established that ErpB and ErpQ were capable of direct interaction with human C1 via specific recognition of the protease subcomponents, using ErpQ we explored a potential mechanism of action for $\mathrm{C} 1$ inhibition. To facilitate clarity in our gel-based cleavage assays and 
to eliminate the GST-tag from the mechanistic analysis, we generated an ErpQ construct lacking this epitope. The "tagless" ErpQ behaved nearly identically in SPR C1s-binding assays and ELISA-based complement assays when compared to GST-ErpQ (Fig S6).

Previously we have shown that BBK32, which binds to $\mathrm{C} 1 \mathrm{r}$ but not $\mathrm{C} 1 \mathrm{~s}$, is capable of directly inhibiting purified C1r enzyme cleavage of C1s proenzyme (28). In contrast, recombinant ErpQ failed to block this reaction at protein concentrations several orders of magnitude greater than the C1r/ErpQ $K_{D}$ (Fig S7A). ErpQ also failed to prevent the cleavage of the small peptidic C1r substrate Z-Gly-Arg-sBzl (60), whereas BBK32 did so readily (Fig S7B). Similarly, unlike futhan, the small molecule active site C1s inhibitor (60), $25 \mu \mathrm{M}$ ErpQ (i.e. , > 5,500 fold over the measured $K_{\mathrm{D}}$, Table 1) failed to inhibit the cleavage of the $\mathrm{C} 1 \mathrm{~s}$ peptidic substrate Z-L-Lys thiobenzyl by C1s, (Fig 3A). Thus, in the C1s/ErpQ complex, the active site of $\mathrm{C} 1 \mathrm{~s}$ remains accessible to a small peptide substrate.

We next tested whether ErpQ was capable of inhibiting C1s-mediated cleavage of native substrates. The cleavage of $\mathrm{C} 2$ or $\mathrm{C} 4$ by purified $\mathrm{C} 1 \mathrm{~s}$ was monitored by SDS-PAGE in the presence of increasing concentrations of ErpQ (Fig 3B,C). Whereas BBK32 failed to block C2 cleavage by C1s (Fig 3B, lane 3) to generate the cleavage product C2b (" $\leftarrow$ C2b"; Fig 3B), ErpQ blocked C1s-mediated C2 proteolysis and the concomitant formation of $\mathrm{C} 2 \mathrm{~b}$ in a dosedependent fashion (Fig. 3B, lanes 6-13). Likewise, while BBK32 failed to prevent C4 cleavage by C1s (Fig 3C, lane 3) to generate the cleavage product C4a' (“ $\leftarrow \mathbf{C 4 \alpha}$ "; Fig 3C), ErpQ did so in a dose-dependent manner (Fig. 3C, lanes 6-13). Densitometry analysis resulted in calculated ErpQ $\mathrm{IC}_{50}$ 's of $1.4 \mu \mathrm{M}$ and $11 \mu \mathrm{M}$ for $\mathrm{C} 2$ and $\mathrm{C} 4$, respectively. The observation that ErpQ inhibited the cleavage of large endogenous $\mathrm{C} 1$ s substrates but not a small peptide $\mathrm{C} 1 \mathrm{~s}$ substrate 
suggests that ErpQ inhibits C1s allosterically, leaving the active site of C1s accessible to small peptides.

\section{ErpB and ErpQ inhibit the classical pathway of complement}

Collectively, the data above identify a novel interaction between surface-expressed $B$. burgdorferi lipoproteins ErpB and ErpQ with human C1 and demonstrate that recombinant ErpQ blocks $\mathrm{C} 1 \mathrm{~s}$ activity. The $\mathrm{CP}$ is initiated by this $\mathrm{C} 1$ activity, so we tested the ability of ErpB and ErpQ to block successive steps in this pathway. Recombinant GST-ErpB or GST-ErpQ fusion proteins were added at increasing concentrations to normal human serum in microtiter wells coated with IgM to initiate $\mathrm{CP}$ activation. The surface deposition of $\mathrm{C} 4 \mathrm{~b}, \mathrm{C} 3 \mathrm{~b}$, and C5b-9, mimicking the fixation of successive components of the CP (59) was measured by ELISA. GSTBBK32 and GST-BB0460 served as positive and negative controls, respectively. Both GSTErpB and GST-ErpQ inhibited the deposition of these three components in a dose-dependent manner, with half-maximal inhibitory concentrations ( $\mathrm{IC}_{50}$ 's) approximately ten-fold higher than the $\mathrm{IC}_{50}$ of GST-BBK32 (Fig 4A-C, Table 2). GST-BB0460 showed no inhibitory activity. As C5b-9 is the membrane attack complex, capable of generating pores in membranes, we further tested each protein for protection of antibody-sensitized sheep red blood cells from CP-mediated lysis. As above, GST-ErpQ and GST-ErpB inhibited lysis in a dose-dependent manner, with an $\mathrm{IC}_{50}$ of 1.5 and $1.6 \mu \mathrm{M}$, respectively, or $\sim 20$-fold higher than the $\mathrm{IC}_{50}$ of GST-BBK32 (Fig 4D, Table 2).

Ectopic production of ErpB and ErpQ protect spirochetes from complement-mediated killing.

The ability of recombinant GST-ErpB and GST-ErpQ to block complement deposition products and prevent lysis of red blood cells by the membrane attack complex suggested that 
these proteins may protect spirochetes from antibody-dependent complement attack. We tested the ability of B. burgdorferi B31-e2 strains that ectopically produce (His-tagged) ErpB or ErpQ (Fig 1A) to resist CP killing, with BBK32 and BB0460 as positive and negative controls, respectively. Based on a previously-described assay to initiate the $\mathrm{CP}(61)$, we incubated these strains with B. burgdorferi-specific polyclonal antibodies, then added normal human serum to provide complement components and lysozyme to facilitate disruption of spirochetal integrity (see Methods). After dilution into BSK-II media and 72-hour incubation to allow for growth of surviving bacteria, we enumerated living spirochetes. Treatment with isotype control antibody or heat-inactivated serum were utilized as negative controls, and survival indices were calculated after normalization to spirochetes surviving treatment with heat-inactivated serum.

As predicted, a B. burgdorferi B31-e2 high-passage strain that ectopically produced the periplasmic protein BB0460 was highly susceptible to antibody-dependent complement killing, with an index of less than $0.3 \%$ (Fig 5E, purple). Conversely, production of BBK32 conferred high-level protection, with an index of $\sim 56 \%$, or $\sim 190$-fold higher than the negative control BB0460 (Fig 5E, blue). Spirochetes producing ErpB or ErpQ displayed survival indices of 9and 56-fold higher, respectively, than the those producing BB0460 (Fig 5E, green and red). Compared to B. burgdorferi B31-e2 producing BB0460, the strain producing ErpQ displayed a six-fold defect in survival index after incubation with isotype control antibody, suggesting that the overproduction of ErpQ may moderately enhance susceptibility of the spirochete to non-CP serum killing. Nevertheless, the dramatically enhanced resistance to CP-mediated killing conferred by ErpB and ErpQ indicates that the inhibition of $\mathrm{C} 1 \mathrm{~s}$ cleavage and inactivation of the $\mathrm{CP}$ observed in biochemical assays reflects an activity that protects bacterial viability. 


\section{Discussion}

Lyme disease spirochetes are typical of other spirochetal pathogens in that they encode many lipoproteins (58). Although the proportion of lipoproteins located in the periplasm varies among spirochetes $(6,69,74,75)$, surface lipoproteins are critical to pathogenesis and provide an important means by which pathogenic spirochetes interact with the host environment and (76, 77). Of the approximately125 lipoproteins encoded by the B. burgdorferi genome, the majority localize to the outer membrane (6), although functions for relatively few of these proteins have been elucidated. Adding to the complexity of understanding lipoprotein function, several of the best characterized B. burgdorferi outer surface lipoproteins, such as OspC and BBK32, have been shown to provide multiple independent functions during murine borreliosis (43-47).

Building on the generation of a comprehensive lipoprotein library (6), we developed a screening methodology to identify novel interactions between host macromolecules and the B. burgdorferi surface lipoproteome expressed in its native environment in the outer membrane of intact spirochetes. This methodology has the potential to uncover diverse host interactions that take place at the spirochete surface and may be valuable in the study of other pathogenic bacteria as well.

As an extracellular pathogen that encounters host blood during both the tick bloodmeal and throughout dissemination and colonization of their vertebrate hosts, Lyme disease spirochetes must prevent complement-mediated opsonization and lysis at multiple stages in the enzootic cycle. Moreover, the complement system employs three distinct pathways for activation that together form a complex host defense. Reflecting this, nearly a dozen different $B$. burgdorferi outer surface lipoproteins have been shown to directly interact with complement components, disrupting their activities $(9,10)$. At least three factors contribute to the multiplicity 
347 of lipoproteins devoted to thwart complement defense. First, distinct borrelial complement

348 evasion proteins block different complement activation pathways. For example, BBK32

349 selectively targets $\mathrm{C} 1 \mathrm{r}$, the initiator protease of the classical pathway, while OspC binds to C4b,

350 the downstream activation product of both the classical and lectin pathways $(15,28,29)$. Second,

351 individual borrelial lipoproteins may target the same host protein but function at different stages

352 of the enzootic cycle. B. burgdorferi CspA and CspZ both bind to factor $\mathrm{H}$ and prevent activation

353 of the alternative pathway, but CspA is expressed exclusively in the tick midgut and prevents the

354 bacteriocidal effects of the bloodmeal, whereas CspZ is produced early in vertebrate infection

355 and fosters the establishment of infection in that host $(26,27,78)$. Finally, although some Lyme

356 disease spirochete strains are restricted to only a single vertebrate, other strains have the capacity

357 to infect multiple vertebrate hosts (62) that encode polymorphic complement components (63,

358 64). Indeed, variation in CspA sequences have been shown to dictate binding to mammalian vs.

359 avian factor $\mathrm{H}$ and the concomitant capacity to infect these two hosts $(27,66)$. Likewise, the

360 production of multiple complement-inactivating proteins may permit the broad host specificity

361 displayed by some B. burgdorferi strains. Thus, the collective activities of multiple complement

362 evasion proteins of $B$. burgdorferi may provide the distinct temporal and spatial needs to thrive

363 in enzootic cycles that involve multiple hosts. Due to the complexity of these interactions. $B$.

364 burgdorferi serves as a useful model for understanding how a wide range of complement

365 inactivation mechanisms together foster the retention of a pathogen in nature.

366 Consistent with the observation that partial functional redundancy is a hallmark of the $B$.

367 burgdorferi complement evasion system, BBK32 was sufficient to protect spirochetes from

368 complement-mediated killing, but $b b k 32$-deficient mutants remained serum resistant (28). Thus,

369 we focused our surface lipoproteome screen on the classical pathway component $\mathrm{C} 1$. We 
370 identified two members of the paralogous Elp protein family, ErpB and ErpQ (from $B$.

371 burgdorferi strain B31), as capable of forming high affinity interactions with the human C1

372 complex (Figs 1, 2, S3); both proteins are antigenic during experimental murine and human

373 infection, indicating that they are produced in vivo $(83,84,85)$. The Erp family encompasses

374 more than 17 genes in strain B31 (86) that share highly homologous leader peptides and DNA

375 sequence at the $5^{\prime}$ end of their operons $(39,42,83)$. However, the amino acid sequences of their

376 mature proteins group them into the OspE-related, OspF-related, and Elp subfamilies that are

377 evolutionarily unrelated (42). Many OspE-related proteins have been shown to bind factor H (87,

$37888,89,90,91)$, and several OspF-related proteins bind to heparan sulfate (32). Our finding that

379 two Elp members bind to complement $\mathrm{C} 1$ further supports the hypothesis of divergent functions

380 among the three subfamilies (42).

ErpQ, like BBK32, prevent antibody-mediated complement activation but target the $\mathrm{C} 1$ complex via distinct means. BBK32 does not bind $\mathrm{C} 1 \mathrm{~s}$, but recognizes both zymogen and activated forms of C1r, blocking its enzymatic activity. In contrast, ErpB and ErpQ bind to both C1r and C1s but selectively recognize activated forms of the proteases (Figs 2, S5). Further, we showed that ErpQ in incapable of blocking C1r activity (Fig S7) but prevents cleavage of both C2 and C4 by

387 activated C1s enzyme (Fig 3B); it seems highly likely that ErpB possesses a similar activity.

388 Finally, ErpQ did not prevent cleavage of small peptide substrates, and is unusual among 389 microbial-derived serine protease inhibitors, such as ecotin or BBK32 (49), which typically target the active site $(79,80)$.

Previous work showed that expression of BBK32 by a high-passage, noninfectious $B$. 
and lectin pathways eliminated this enhancement, indicating that BBK32 blocked one or both pathways. To confirm that the C1-binding activities of BBK32, ErpB and ErpQ specifically blocked classical complement killing, we triggered this pathway by treating high-passage strains that ectopically produce these proteins with anti-B. burgdorferi antibody. Whereas BBK32, ErpB and ErpQ provided no survival advantage when spirochetes were treated with serum supplemented with isotype control antibody, all three lipoproteins promoted survival when incubated with specific antibody, indicating that the C1r- or C1s-inhibitory activities of BBK32 or ErpB and ErpQ, respectively, protected spirochetes from classical complement killing. BBK32 provided the greatest degree of protection, enhancing the survival index 190-fold relative to BB0460, compared to 56-fold and 9-fold for ErpQ and ErpB, respectively, (Fig 5). Notably, BBK32 and ErpQ appeared to be expressed at much higher levels than ErpB (Fig 2A). In addition, BBK32 inhibited $\mathrm{C} 4 \mathrm{~b}$ and $\mathrm{C} 3 \mathrm{~b}$ in vitro deposition and complement-mediated $\mathrm{RBC}$ hemolysis at $\sim 10$-fold lower concentrations than ErpB or ErpQ (Fig 4).

The innate and adaptive immune system intersect at the level of the classical pathway of complement when antibody-antigen immune complexes are recognized by complement $\mathrm{C} 1$, triggering the complement cascade. Blocking complement $\mathrm{C} 1$ may be critical for $B$. burgdorferi persistence in immunocompetent hosts, which generate a specific antibody response during chronic infection. This activity might also be required to establish infection in a previously infected host, or, given that natural antibodies recognize the Lyme disease spirochete (50), in a naïve host.

ErpB and ErpQ display identical biochemical activities, and no evidence to-date has indicated divergent expression patterns between the two genes, raising the possibility that they are functionally redundant. In addition, other Elp family members such as ErpX and ErpM 
416 (which is as closely related to ErpB and ErpQ as they are to each other; Table S3) did not bind

417 human C1 (Fig 1A). Complement C1 is polymorphic among vertebrates, and whether these Elp's

418 recognize $\mathrm{C} 1$ of other $B$. burgdorferi hosts, perhaps contributing to host specificity, remains to

419 be tested (81). Historically, comprehensive analysis of B. burgdorferi gene families has been

420 limited by the difficulty of genetic manipulation of infectious strains. However, recent adaptation

421 of CRISPRi to this pathogen (82) may enable future comprehensive examinations of the role of

422 Elp proteins during the enzootic lifecycle of B. burgdorferi.

423 
Materials and Methods

425

426

427

428

429

430

431

432

433

434

435

436

437

438

439

440

441

442

443

444

445

446

\section{Expression plasmid cloning and protein purification}

All primers used in this study are listed in TableS4. To generate expression plasmids encoding N-terminal GST fusions of ErpB, ErpQ, BBK32, and BB0460, genomic DNA was first prepared from these B. burgdorferi B31-e2 expression strains using the DNeasy Blood and Tissue Kit (Qiagen). The open reading frame (lacking the putative lipoprotein signal sequence) of each gene was PCR amplified using Q5 Hot Start Master Mix (New England Biolabs). Each PCR fragment, except for the one encoding ErpB, was engineered into the MCS of the pGEX4T2 expression vector (GE Healthcare Life Sciences) using BamHI and XmaI restriction sites. For $\operatorname{erp} B$, which contains an internal BamHI restriction site, EcoRI and XmaI were used. Inserts were ligated into vector pGEX4T2 and the ligations were transformed into E. coli DH5 $\alpha$ as previously described (67). Transformants were confirmed by BamHI/EcoRI and XmaI restriction digest of the plasmids, followed by gel electrophoresis on a $1 \%$ agarose gel for one hour at $75 \mathrm{~V}$. Clones containing the correct insert were Sanger sequenced using an ABI 3130XL automated sequencer (Applied Biosciences). Confirmed plasmids were subsequently transformed into E. coli BL21(DE3) as previously described (67).

To purify GST-tagged proteins, E. coli BL21(DE3) cells encoding the appropriate plasmid were grown in broth culture with aeration at $37^{\circ} \mathrm{C}$ to an OD600nm of 0.6 , then induced with $1 \mathrm{mM}$ IPTG (Sigma Aldrich) with aeration at room temperature overnight. The following day, cells were lysed using an M-110S Microfluidizer (Microfluidics) and proteins were purified using glutathione chromatography according to the manufacturer's instructions (GE Healthcare Life Sciences). To confirm the size and purity of purified recombinant protein, $25 \mu$ of column eluate was resolved by SDS-PAGE on a 4-20\% gradient polyacrylamide gel run at $75 \mathrm{~V}$ for 1.5 
447 hours. Gels were then stained for 30 minutes with Coomassie blue solution [0.25\% (w/v)

448 Coomassie brilliant blue R-250, 45\% (v/v) methanol, 10\% (v/v) glacial acetic acid], rinsed in

449 deionized water, and destained for two hours with destain solution [40\% (v/v) methanol, 10\%

450 (v/v) glacial acetic acid]. Stained gels were imaged using a Syngene G:Box XR5 imager.

451

STOP and NotI site using the pGEX4T2 construct containing ErpQ as template. Subsequent

used in study were assessed for purity by SDS-PAGE prior to use in assays.

Bacterial strains, plasmids, and lipoprotein gain-of function library

E. coli strains DH5 $\alpha$ and BL21(DE3) were cultured as described above. An epitope-

464 clones (Table S1). Ectopic expression of each lipoprotein-encoding gene is driven by the $B$.

465 burgdorferi flaB constitutive promoter. The library was arrayed in multiple 96-well, sterile, flat

466 bottom plates at a concentration of $1 \times 10^{7}$ spirochetes/well $\left(1 \times 10^{8}\right.$ per $\left.\mathrm{ml}\right)$ and stored at $-80^{\circ} \mathrm{C}$ in 467 BSK-II with 20\% (v/v) glycerol.

468 Quantitation of binding of gain-of-function library clones to immobilized substrates 
Binding of gain-of-function library clones to immobilized substrates was measured using

470 a modification of a previously-described ELISA-based assay (51). One $\mu \mathrm{g} /$ well purified BSA

471 (Sigma Aldrich), or human derived fibronectin (Corning) or C1 proteins (Complement

472 Technologies) in coating buffer [0.1M sodium bicarbonate, $\mathrm{pH}$ 9.6] was used to coat wells of an

473 uncoated 96-well ELISA plate (Nunc Maxisorp) at $4^{\circ} \mathrm{C}$ overnight. On the same day, a single 96-

474 well plate containing the gain of function library was thawed at room temperature and 475 centrifuged $(1,250 \times \mathrm{g}, 15 \mathrm{~min}, \mathrm{RT})$ to pellet the spirochetes. The supernatant was discarded, and 476 the cells were resuspended in $200 \mu \mathrm{l} /$ well of BSK-II and allowed to recover under normal growth 477 conditions. The following day, $80 \mu \mathrm{l}\left(\sim 4 \times 10^{6}\right.$ cells $)$ of culture from each well of the 96 -well plate 478 were transferred to a new plate and centrifuged $(1,250 \times \mathrm{g}, 15 \mathrm{~min}, \mathrm{RT})$. The supernatant was 479 discarded, and the cells were resuspended in $200 \mu \mathrm{l} /$ well HBS-DB [25 mM HEPES, $105 \mathrm{mM}$ 480 sodium chloride, $1 \mathrm{mM}$ manganese chloride, $1 \mathrm{mM}$ magnesium chloride, $0.1 \%(\mathrm{w} / \mathrm{v})$ dextrose, $4810.2 \%(\mathrm{w} / \mathrm{v}) \mathrm{BSA}, \mathrm{pH} 7.8)]$. The previously coated 96-well plate was washed three times with 482 PBS-T [10 $\mathrm{mM}$ disodium phosphate, $1.8 \mathrm{mM}$ monopotassium phosphate, $137 \mathrm{mM}$ sodium 483 chloride, $2.7 \mathrm{mM}$ potassium chloride, $0.05 \%$ (v/v) Tween-20, $\mathrm{pH} 7.4$ ] and was blocked with 200 $484 \mu \mathrm{l} /$ well of Ultrablock (BioRad) for 1.5 hours.

$486 \mu \mathrm{l} /$ well $\left(\sim 1 \times 10^{6}\right.$ spirochetes $)$ of the resuspended gain-of-function library. The inoculated plate 487 was centrifuged $(1,250 \times \mathrm{g}, 15 \mathrm{~min}, \mathrm{RT})$ to force the spirochetes into contact with the proteins 488 coated on the bottoms of the wells. The plates were then incubated for one hour at room 489 temperature, followed by three washes to remove unbound spirochetes. Bound spirochetes were affixed to the surface of the well by adding $4 \%$ formaldehyde (v/v) for 20 minutes at room 
temperature. After fixation, the formaldehyde was removed, and the plates were air dried on the bench top overnight.

The following day fixed spirochetes were permeabilized with $50 \mu \mathrm{l} /$ well of ice-cold methanol for 10 minutes at $-20^{\circ} \mathrm{C}$. Methanol was then removed and the plates were air dried for several minutes. Wells were then blocked with $200 \mu \mathrm{l} /$ well of $5 \%(\mathrm{w} / \mathrm{v})$ non-fat dry milk in PBS$\mathrm{T}$ for one hour, followed by washing. To detect spirochete binding, wells were incubated with a 1:800 dilution of a polyclonal rabbit $\alpha$-Bb antibody (Abcam, ab20118) for one hour at room temperature, then washed and probed with a 1:2,000 dilution of an $\alpha$-rabbit alkaline phosphatase conjugated antibody (Sigma Aldrich, cat \# A3687) for one hour at room temperature. Wells were then washed and signal developed using the SigmaFast pNpp reagent (Sigma Aldrich). The assay readout (OD405nm) was taken every minute for 15 minutes using a BioTek Synergy HT plate reader and Gen5 software. Bacterial binding is expressed as the Vmean of $\Delta \mathrm{OD}_{405 \mathrm{~nm}}$, calculated by determining the slope of the [OD405nm vs. time] best fit line across the linear portion of the 15-minute kinetic assay. All experiments were repeated at least twice.

\section{Quantitative ELISA to assess B. burgdorferi lipoprotein binding to purified human C1}

To quantitate the ability of B. burgdorferi lipoproteins to bind purified components of the C1 complex, we adapted a previously described quantitative ELISA-based assay (52). One $\mu \mathrm{g} /$ well of purified human C1, C1q, C1r, or C1s proteins (Complement Technologies), or BSA (Sigma-Aldrich) as a negative control, were coated onto wells of an uncoated 96-well ELISA plate (Nunc Maxisorp) overnight at $4^{\circ} \mathrm{C}$ in coating buffer, as described above. The next day, plates were washed three times with PBST [10 $\mathrm{mM}$ disodium phosphate, $1.8 \mathrm{mM}$ monopotassium phosphate, $137 \mathrm{mM}$ sodium chloride, $2.7 \mathrm{mM}$ potassium chloride, $0.05 \%$ (v/v) Tween-20, pH 7.4] and blocked with 5\% (w/v) nonfat dry milk in PBST. Plates were then 
washed, and $100 \mu \mathrm{l} /$ well of four-fold dilutions of GST-tagged BBK32, ErpB, ErpQ, or BB0460

515

516

517

518

519

520

521

522

523

524

525

526

527 software.

528

529

530

531

532

533

534

535

536

proteins, resulting in a range of concentrations from $1 \mu \mathrm{M}$ to $240 \mathrm{pM}$, were added to the ELISA

plate, which was then incubated for one hour at room temperature. Wells were washed and

probed with $100 \mu \mathrm{l} /$ well of a goat $\alpha$-GST antibody (GE Healthcare Life Sciences, 27457701V)

diluted 1:800 and incubated for one hour at room temperature. Wells were washed again and

probed with $100 \mu \mathrm{l} /$ well of a $\alpha$-goat alkaline phosphatase conjugated antibody (Sigma Aldrich, A4187) diluted 1:2,000 and incubated for one hour at room temperature. Wells were washed a

final time and the assay was developed using the SigmaFast pNpp reagent (Sigma Aldrich).

OD405nm was read every minute for 15 minutes in a BioTek Synergy HT plate reader using

Gen5 software. Substrate binding is expressed as the Vmean of $\Delta$ OD405nm, calculated by

determining the slope of the [OD405nm vs. time] best fit line across the linear portion of the 15-

minute kinetic assay. All experiments were repeated two to four times. KD was quantified by a

saturated binding parameter non-linear regression analysis performed using GraphPad Prism 6.0

\section{Surface plasmon resonance}

Binding of $\mathrm{C} 1$ and its sub-components to GST-ErpB and GST-ErpQ was performed at $25^{\circ} \mathrm{C}$ using a Biacore T200 (GE Healthcare) as previously described (Garcia 2016), with the following modifications. GST-ErpB and GST-ErpQ were amine coupled to the CMD200 (Xantec bioanalytics) at $10 \mu \mathrm{g} / \mathrm{ml}$ in $10 \mathrm{mM}$ sodium acetate $\mathrm{pH}$ 4.0. Final immobilization densities shown in resonance units (RU) were 555.1 (GST-ErpB) and 451.1 RU (GST-ErpQ), and proenzyme studies were performed on 232.2 (GST-ErpB) and 485.7 (GST-ErpQ). C1s single cycle experiments had immobilization densities of 1181.3 (GST-ErpQ) and 1158.9 (ErpQ $19-343$ ). HBS-T-Ca ${ }^{2+}\left(20 \mathrm{mM}\right.$ HEPES (pH 7.3), $140 \mathrm{mM} \mathrm{NaCl}, 0.005 \%$ (v/v) Tween 20, $5 \mathrm{mM} \mathrm{CaCl}_{2}$ ) 
537 was used as the running buffer and a flowrate of $30 \mu 1 \mathrm{~min}^{-1}$ was used in all experiments. All analytes were buffer exchanged into running buffer prior to experimentation.

540 Technologies) was injected over flow cells in a two-fold concentration series: $0.59,1.2,2.3,4.7$,

$5419.4,18.8,37.5,75$, and $150 \mathrm{nM}$ for $120 \mathrm{sec}$, followed by $180 \mathrm{sec}$ dissociation. The same

542 approach was used for proenzyme $\mathrm{C} 1 \mathrm{r}, \mathrm{C} 1 \mathrm{r}$ enzyme, proenzyme $\mathrm{C} 1 \mathrm{~s}$, and $\mathrm{C} 1 \mathrm{~s}$ enzyme

543 (Complement Technologies), using a two-fold concentration series of 0.39, 0.78, 1.6, 3.1, 6.3,

$54413,25,50,100$, and $200 \mathrm{nM}$. Surfaces were then regenerated by injecting $2 \mathrm{M} \mathrm{NaCl}$ for 60 sec 3

545 times consecutively, bringing the response to baseline. Alternatively, single cycle analysis was

546 performed with a five-fold concentration series $0,0.8,4,20,100 \mathrm{nM}$ with association times

547 between each injection of $120 \mathrm{sec}$ a final dissociation time of $600 \mathrm{sec}$. Kinetic analyses were

548 performed on each sensorgram series using the Biacore T200 Evaluation Software 3.1 (GE

549 Healthcare) and a 1:1 (Langmuir) binding model.

550

551

552

553

554

555

556

557

558
Proteinase K treatment, conventional western and far western immunoblotting

Surface proteolysis of expressed lipoproteins was performed as previously described (34). Briefly, $1 \times 10^{8}$ spirochetes were washed three times in HBS-DB and resuspended in $100 \mu 1$ of HBS-DB. Spirochetes were then treated with $40 \mu \mathrm{g} / \mathrm{ml}$ (final concentration) of pronase (Sigma) for one hour at room temperature. Reactions were inactivated with $2 \mathrm{mM}$ phenylmethanesulfonyl fluoride (PMSF) (Sigma Aldrich) and cells were lysed by boiling for ten minutes in Laemmli buffer (34). Bacterial lysates were resolved by SDS-PAGE on a 4-20\% gradient polyacrylamide gel at $75 \mathrm{~V}$ for 1.5 hours. After electrophoresis, samples were transferred to a PVDF membrane and used for western immunoblotting. 
Conventional western immunoblotting was performed by blocking the PVDF membrane

560

561

562

563

564

565

566

567

568

569

570

571

572

$573(\mathrm{v} / \mathrm{v})$ Tween-20, 5\% (w/v) nonfat dry milk] overnight at $4^{\circ} \mathrm{C}$. The next day, membranes were

574 washed in PBS-T and were incubated with $\alpha$-C1q (Complement Technologies, A200), $\alpha$-C1r

575 (R\&D Systems, MAB1807), or $\alpha-C 1 s$ (R\&D Systems, MAB2060) antibodies, following the

576 manufacturer's recommended dilutions for western blotting. Following washing, immunoblots

577 were probed with the appropriate secondary $\alpha$-goat (C1q) (Sigma Aldrich, A5420) or $\alpha$-mouse

$578(\mathrm{C} 1 \mathrm{r} / \mathrm{s})$ (Promega, W402B) antibodies conjugated to horseradish peroxidase, at a dilution of 1:5000. Immune complexes were detected using the SuperSignal West Pico Chemiluminescent 
Inhibition of erythrocyte hemolysis by recombinant B. burgdorferi lipoproteins

Inhibition of $\mathrm{CP}$-mediated erythrocyte hemolysis by recombinant $B$. burgdorferi lipoproteins was assayed using a modified version of the previously described classical pathway hemolytic assay $(28,54)$. Normal human serum (Complement Technologies) was diluted to $2.3 \%$ (v/v) in CP/LP reaction buffer. GST-tagged ErpB, ErpQ, BBK32, or BB0460 proteins were serially diluted two-fold, $125 \mu \mathrm{l}$ of each dilution was mixed with $125 \mu \mathrm{l}$ of the diluted serum, and the mixtures were incubated at room temperature for one hour. During incubation, $5 \mathrm{ml}$ of preopsonized sheep erythrocytes (Complement Technologies) were centrifuged (400 $\times \mathrm{g}, 3$ minutes, $4^{\circ} \mathrm{C}$ ) and washed twice in $\mathrm{CP} / \mathrm{LP}$ reaction buffer. After washing, erythrocytes were resuspended in $5 \mathrm{ml}$ of $\mathrm{CP} / \mathrm{LP}$ buffer and $40 \mu \mathrm{l}$ of the erythrocyte suspension were added to each of the incubated serum-protein mixtures. These reactions were incubated for one hour at room temperature, gently vortexing every 15 minutes to ensure that erythrocytes remained in suspension. Following incubation, samples were centrifuged $\left(600 \times \mathrm{g}, 3\right.$ minutes, $\left.4^{\circ} \mathrm{C}\right)$ and 200 $\mu \mathrm{l}$ of supernatant from each sample was collected and the OD405nm was measured in a BioTek Synergy HT plate reader using Gen5 software.

\section{Inhibition of C3d deposition by recombinant B. burgdorferi lipoproteins}

To determine the effect of recombinant B. burgdorferi lipoproteins on CP-mediated deposition of C3d, we adapted a previously described ELISA based assay $(28,55)$. 96-well ELISA plates (Nunc Maxisorp) were coated with 300 ng human IgM (CP initiator) (Athens Research \& Technology) in $100 \mu \mathrm{l} /$ well of coating buffer (see above) overnight at $4^{\circ} \mathrm{C}$. The following day, the plates were washed three times with PBS-T (see above) and were blocked with $200 \mu \mathrm{l}$ of $1 \%(\mathrm{w} / \mathrm{v})$ BSA (Sigma Aldrich) in PBS-T for one hour at room temperature. Normal human serum (Complement Technologies) was diluted to 2\% (v/v) in CP reaction buffer 
605 [20 mM HEPES (pH 7.3), $140 \mathrm{mM}$ sodium chloride, $150 \mu \mathrm{M}$ calcium chloride, $500 \mu \mathrm{M}$ 606 magnesium chloride, 0.1\% (w/v) gelatin]. GST-tagged ErpB, ErpQ, BBK32, or BB0460 proteins were serially diluted two-fold and each dilution was mixed 1:1 with the above serum dilutions.

$608100 \mu \mathrm{l}$ of each mixture was added to the complement initiator-treated wells. Plates were 609 incubated in the presence of $5 \% \mathrm{CO} 2$ for one hour at $37^{\circ} \mathrm{C}$, followed by three washes with PBS-

610 T. Following deposition, wells were blocked with $200 \mu \mathrm{l} /$ well of $5 \%(\mathrm{w} / \mathrm{v})$ nonfat dry milk in 611 PBS-T for one hour at room temperature, followed by three washes with PBS-T. Wells were then 612 probed with $100 \mu \mathrm{l} /$ well of a mouse $\alpha-\mathrm{C} 3 \mathrm{~d}$ (Abcam, ab17453) primary antibody diluted 1:500 613 and incubated for one hour at room temperature. Wells were washed again and probed with 100 $614 \mu 1 /$ well of a $\alpha$-mouse alkaline phosphatase-conjugated secondary antibody (Sigma Aldrich, 615 A4187) diluted 1:2,000 and incubated for one hour at room temperature. Wells were washed a 616 final time and developed using the SigmaFast pNpp reagent (Sigma Aldrich). OD405nm 617 readings were taken every minute for 15 minutes in a BioTek Synergy HT plate reader using 618 Gen5 software. Substrate binding is expressed as the Vmean of $\Delta \mathrm{OD}_{405 \mathrm{~nm}}$, which is calculated by 619 determining the slope of the [OD405nm vs. time] best fit line across the linear portion of the 15620 minute kinetic assay. All experiments were repeated two to four times. polypropylene microplates (Grenier bio-one). All subsequent steps were then washed three 626 times, $100 \mu \mathrm{l}$ volumes, with TBS-T (50mM Tris ( $\mathrm{pH} 8.0), 150 \mathrm{mM} \mathrm{NaCl}, 0.05 \%$ (v/v) TritonX627 100). Unbound regions of the plate were then blocked with PBS-T-BSA (137mM NaCl, $2.7 \mathrm{mM}$ 
$628 \mathrm{KCl}, 10 \mathrm{mM} \mathrm{Na}_{2} \mathrm{HPO}_{4}, 1.8 \mathrm{mM} \mathrm{KH}_{2} \mathrm{PO}_{4}, 1 \%(\mathrm{w} / \mathrm{v})$ bovine serum albumin, and $0.05 \%(\mathrm{v} / \mathrm{v})$

629 Tween-20) for $1 \mathrm{~h}$ at $37^{\circ} \mathrm{C}$. Classical pathway-mediated complement activation was then induced

630 by adding 2\% final pooled Normal Human Serum (Innovative Research) and a two-fold dilution

631 series of GST-ErpB/GST-ErpQ/GST-BB0460 or untagged proteins BBK32-C/ErpQ19-343,

632 respectively, in CP Buffer (20 mM HEPES (pH 7.3), 0.1\% (w/v) gelatin type A, $140 \mathrm{mM} \mathrm{NaCl,}$

$6332 \mathrm{mM} \mathrm{CaCl}_{2}, 0.5 \mathrm{mM} \mathrm{MgCl}_{2}$ ) with incubation at $37^{\circ} \mathrm{C}$ for $1 \mathrm{hr}$. A 1:300 dilution anti-C4 antibody

634 (HYB 162-02) (Santa Cruz Biotechnology) in CP Buffer incubated at $37^{\circ} \mathrm{C}$ for 1 hour was used

635 to detect complement activation. A 1:3000 dilution of goat anti-mouse HRP secondary antibody

636 (Thermo Scientific) was then used at room temperature with light rocking for 1 hour. Activation

637 of HRP conjugated antibody was detected by room temperature 1-step Ultra TMB ELISA

638 (Thermo Scientific) for 10 min with rocking in the dark. The reaction was then stopped with the

639 addition of $0.16 \mathrm{~N}$ sulfuric acid and the absorbance measured at $450 \mathrm{nM}$ on an EnSight

640 multimode plate reader (PerkinElmer). Data were in-column normalized using cells containing

641 serum only or no serum with buffer addition were used as $100 \%$ and $0 \%$ signal, respectively. All

642 experiments were performed in triplicate and $\mathrm{IC}_{50}$ values were determined using a variable four-

643 parameter nonlinear regression analysis using GraphPad Prism 8.1.2.

644 Inhibition of C1r and C1s enzyme activity by synthetic peptide cleavage

$645 \mathrm{C} 1 \mathrm{r}$ enzyme and C1s enzyme assays were performed in $\mathrm{HBS}_{-\mathrm{Ca}}{ }^{2+}(20 \mathrm{mM} \mathrm{HEPES}$

646 (pH7.3), $140 \mathrm{mM} \mathrm{NaCl}, 5 \mathrm{mM} \mathrm{CaCl}_{2}$ ). C1r enzyme assays were completed by monitoring the

647 autolytic activation of C1r proenzyme by adding GST-ErpB or GST-ErpQ, at a concentration of

$64825 \mu \mathrm{M}$, with $25 \mathrm{nM}$ C1r proenzyme. Subsequent addition of $300 \mu \mathrm{M}$ Z-Gly-Arg thiobenzyl (MP

649 Biomedicals) and $100 \mu \mathrm{M}$ 5,5'-dithiobis(2-nitrobenzoic acid) (DTNB) (TCI) just prior to

650 measurement for a final $80 \mu \mathrm{l}$ reaction volume (56). C1s enzyme assays were performed by 
651 adding GST-ErpB or GST-ErpQ, at a concentration of $25 \mu \mathrm{M}$, to $100 \mu \mathrm{M}$ Z-L-Lys thiobenzyl

652 and $100 \mu \mathrm{M}$ DTNB. Just prior to measurement, $6.25 \mathrm{nM} \mathrm{C1s} \mathrm{enzyme} \mathrm{was} \mathrm{added} \mathrm{for} \mathrm{a} \mathrm{final} 80 \mu 1$

653 reaction volume. Absorbance measurements were performed at $412 \mathrm{nM}$ on a Versamax

654 multimode plate reader (Molecular Devices) with plate reads occurring every $30 \mathrm{sec}$ at $28^{\circ} \mathrm{C}$ for

$6553 \mathrm{hrs}(\mathrm{C} 1 \mathrm{r})$ and $37^{\circ} \mathrm{C}$ for $1 \mathrm{hr}(\mathrm{C} 1 \mathrm{~s})$. Data were in-column normalized by including the $\mathrm{C} 1 \mathrm{r}$

656 proenzyme or C1s enzyme with substrate as 100\% signal, or just peptide and DTNB as $0 \%$.

657 Gel-Based Inhibition of C1s-Mediated C2/C4 Cleavage Assay

658 To demonstrate inhibition of $\mathrm{C} 1 \mathrm{~s}$ mediated cleavage of $\mathrm{C} 2$ or $\mathrm{C} 4$ a $10 \mu \mathrm{L}$ reaction in $659 \mathrm{HBS}_{-\mathrm{Ca}^{2+}}(10 \mathrm{mM}$ HEPES (pH 7.3), $140 \mathrm{mM} \mathrm{NaCl}, 5 \mathrm{mM} \mathrm{CaCl}$ ) was made by adding $6.25 \mathrm{nM}$ 660 C1s enzyme with twofold dilutions of ErpQ $19-343$ from 25,000 nM to $390 \mathrm{nM}$ with subsequent 661 addition of $1.25 \mu \mathrm{L}$ of $\mathrm{C} 4(1 \mathrm{mg} / \mathrm{mL})$ or $\mathrm{C} 2(0.5 \mathrm{mg} / \mathrm{mL})$ (Complement Technologies). The 662 reaction proceeded at $37^{\circ} \mathrm{C}$ for 1 hour and was stopped by the addition of $5 \mu \mathrm{L}$ Laemmli buffer 663 followed by boiling for 5 min. 10\% SDS-PAGE gels were utilized with Coomassie staining. Gel 664 imaging was completed on a ChemiDocTM XRS+ (Bio-Rad). Gels are representative of three 665 independent experiments.

666

Gel-based C2/C4 inhibition assays were subjected to further quantitative analysis with

667 Image $\mathrm{Lab}^{\mathrm{TM}}$ (Bio-Rad). Lanes and bands were manually selected and analyzed as follows. C4 $\alpha^{\prime}$

668 fragments were in lane normalized to $\mathrm{C} 4 \mathrm{~b}$ band and the background adjusted ratios are shown.

$669 \mathrm{C} 2 \mathrm{~b}$ bands were in lane corrected for total $\mathrm{C} 2(\mathrm{C} 2+\mathrm{C} 2 \mathrm{~b}+\mathrm{C} 2 \mathrm{a}) .100 \%$ cleavage was constrained

670 to $\mathrm{C} 1 \mathrm{~s}+\mathrm{C} 2 / \mathrm{C} 4$ control. Proenzyme $\mathrm{C} 1 \mathrm{~s}$ bands were normalized to in lane $\mathrm{C} 1 \mathrm{~s}$ light chain. In the 671 event of no detection of a band a band was placed at the appropriate analysis molecular weight.

672 A normalized four-parameter nonparametric response was analyzed in GraphPad v8.4. 
Gel-based C2/C4 inhibition assays were subjected to further quantitative analysis with

674 Image LabTM (Bio-Rad). Lanes and bands were manually selected and analyzed as follows.

$675 \mathrm{C} 4 \alpha^{\prime}$ fragments were in lane normalized to $\mathrm{C} 4 \mathrm{~b}$ band and the background adjusted ratios are

676 shown. $\mathrm{C} 2 \mathrm{~b}$ bands were in lane corrected for total $\mathrm{C} 2(\mathrm{C} 2+\mathrm{C} 2 \mathrm{~b}+\mathrm{C} 2 \mathrm{a}) .100 \%$ cleavage was

677 constrained to $\mathrm{C} 1 \mathrm{~s}+\mathrm{C} 2 / \mathrm{C} 4$ control. Proenzyme $\mathrm{C} 1 \mathrm{~s}$ bands were normalized to in lane $\mathrm{C} 1 \mathrm{~s}$ light

678 chain. In the event of no detection of a band a band was placed at the appropriate analysis

679 molecular weight. A normalized four-parameter nonparametric response was analyzed in

680 GraphPad v8.4.

681

Gel-Based Inhibition of C1r-Mediated Proenzyme C1s Cleavage Assay

682

Enzymatic inhibition assays were performed as previously described, with the following

modifications (28). A $10 \mu \mathrm{L}$ reaction in HBS-Ca2+ (10 mM HEPES (pH 7.3), $140 \mathrm{mM} \mathrm{NaCl,} 5$

684

$\mathrm{mM} \mathrm{CaCl}_{2}$ ) was prepared by adding $1000 \mathrm{nM} \mathrm{C1r}$ to with twofold dilutions of ErpQ19-343 from

$68525,000 \mathrm{nM}$ to $390 \mathrm{nM}$ and finally $1 \mu \mathrm{g}$ proenzyme $\mathrm{C} 1 \mathrm{~s}$. The reaction was incubated at $37^{\circ} \mathrm{C}$ for

6861 hour and was stopped by the addition of $5 \mu \mathrm{L}$ Laemmli buffer followed by boiling for $5 \mathrm{~min}$.

687 SDS-PAGE analysis was completed as in $\mathrm{C} 2 / \mathrm{C} 4$ cleavage assay. Gel is representative of three 688 independent experiments.

689 Classical pathway-mediated serum-killing assay

$690 \quad 1 \times 10^{9}$ B31-e2 spirochetes expressing ErpB, ErpQ, BBK32, or BB0460 were harvested in 691 late $\log$ phase by centrifugation $(4,000 \times \mathrm{g}, 15 \mathrm{~min})$. Supernatant was discarded and cell pellets 692 were washed three times in CP buffer [20 mM HEPES (pH 7.3), $140 \mathrm{mM} \mathrm{NaCl}, 150 \mu \mathrm{M} \mathrm{CaCl}$, $693500 \mu \mathrm{M} \mathrm{MgCl} 2,0.1 \%$ gelatin]. After resuspending the pellet in $1 \mathrm{ml}$ of $\mathrm{CP}$ buffer, the cells were 694 split into three tubes containing $5 \times 10^{7}$ spirochetes each. $4 \mu \mathrm{g}$ of an $\alpha-B$. burgdorferi antibody 
(Abcam, ab20950) was added to two tubes, while its isotype control (Abcam, ab171870) was added to the third. Cell suspensions were incubated at room temperature for 1 hour, rocking.

Following incubation, the cells were pelleted, washed three times in CP buffer, and resuspended in $625 \mu \mathrm{l}$ of $\mathrm{CP}$ buffer. From one of the $\alpha-\mathrm{Bb}$ antibody tubes, as well as from the isotype control tube, $1 \times 10^{7}$ spirochetes $(125 \mu$ of cell suspension) was dispensed into tubes containing $125 \mu \mathrm{l}$ of $40 \%$ normal human serum (in CP buffer), supplemented with $20 \mu \mathrm{g} / \mathrm{ml}$ lysozyme (Sigma, L6876), in triplicate. $125 \mu \mathrm{l}$ of cell suspension from the other $\alpha$-Bb antibody tube was dispensed into tubes containing $125 \mu \mathrm{l}$ of $40 \%$ heat-inactivated human serum (in CP buffer), supplemented with $20 \mu \mathrm{g} / \mathrm{ml}$ lysozyme, in triplicate. Tubes were all mixed thoroughly by hand and incubated at $37^{\circ} \mathrm{C}$, standing, for 4 hours.

Following the second incubation, the entire $250 \mu \mathrm{l}$ of the serum-cell suspension mixture was transferred into a culture tube containing $2.25 \mathrm{ml}$ of BSK-II, supplemented with the appropriate antibiotics. These cultures were allowed to grow out for 72 hours in normal growth conditions. After 72 hours of growth, the cultures were counted in duplicate by dark field microscopy. Samples were normalized to triplicate counts from the heat-inactivated human serum samples.

\section{Acknowledgments}

Research reported in this publication was supported by the National Institute of Allergy and Infectious Diseases of the National Institutes of Health under award number R01AI146930 (B.L.G), R01AI121401 (JML), K12GM133314 (JDQ). We thank Yi-Pin Lin and Jon Skare for invaluable discussion, and Brian Stevenson for providing anti-Erp antibodies.

\section{References}

1. Kugeler KJ, Schwartz AM, Delorey MJ, Mead PS, Hinckley AF. Estimating the Frequency of Lyme Disease Diagnoses, United States, 2010-2018. Emerg Infect Dis. 
720

721

722

723

724

725

726

727

728

729

730

731

732

733

734

735

736

737

738

739

740

741

742

743

744

745

746

747

748

749

750

751

752

753

754

755

756

2. Gilmore RD Jr, Piesman J. Inhibition of Borrelia burgdorferi migration from the midgut to the salivary glands following feeding by ticks on OspC-immunized mice. Infect Immun. 2000;68(1):411-414. doi:10.1128/IAI.68.1.411-414.2000

3. Pal U, Yang X, Chen M, et al. OspC facilitates Borrelia burgdorferi invasion of Ixodes scapularis salivary glands. J Clin Invest. 2004;113(2):220-230. doi:10.1172/JCI19894

4. Coburn J, Garcia B, Hu LT, et al. Lyme Disease Pathogenesis. Curr Issues Mol Biol. 2021;42:473-518. doi:10.21775/cimb.042.473

5. Radolf JD, Caimano MJ, Stevenson B, Hu LT. Of ticks, mice and men: understanding the dual-host lifestyle of Lyme disease spirochaetes. Nat Rev Microbiol. 2012;10(2):87-99.

Published 2012 Jan 9. doi:10.1038/nrmicro2714

6. Dowdell AS, Murphy MD, Azodi C, et al. Comprehensive Spatial Analysis of the Borrelia burgdorferi Lipoproteome Reveals a Compartmentalization Bias toward the Bacterial Surface. J Bacteriol. 2017;199(6):e00658-16. Published 2017 Feb 28. doi:10.1128/JB.00658-16

7. Caine JA, Coburn J. Multifunctional and Redundant Roles of Borrelia burgdorferi Outer Surface Proteins in Tissue Adhesion, Colonization, and Complement Evasion. Front Immunol. 2016;7:442. Published 2016 Oct 21. doi:10.3389/fimmu.2016.00442

8. Lin YP, Li L, Zhang F, Linhardt RJ. Borrelia burgdorferi glycosaminoglycan-binding proteins: a potential target for new therapeutics against Lyme disease. Microbiology (Reading). 2017;163(12):1759-1766. doi:10.1099/mic.0.000571

9. Skare JT, Garcia BL. Complement Evasion by Lyme Disease Spirochetes. Trends Microbiol. 2020;28(11):889-899. doi:10.1016/j.tim.2020.05.004

10. Lin YP, Frye AM, Nowak TA, Kraiczy P. New Insights Into CRASP-Mediated Complement Evasion in the Lyme Disease Enzootic Cycle. Front Cell Infect Microbiol. 2020;10:1. Published 2020 Jan 30. doi:10.3389/fcimb.2020.00001

11. Merle NS, Church SE, Fremeaux-Bacchi V, Roumenina LT. Complement System Part I Molecular Mechanisms of Activation and Regulation. Front Immunol. 2015;6:262. Published 2015 Jun 2. doi:10.3389/fimmu.2015.00262

12. Merle NS, Noe R, Halbwachs-Mecarelli L, Fremeaux-Bacchi V, Roumenina LT. Complement System Part II: Role in Immunity. Front Immunol. 2015;6:257. Published 2015 May 26. doi:10.3389/fimmu.2015.00257

13. Walport MJ. Complement. First of two parts. N Engl J Med. 2001;344(14):1058-1066. doi:10.1056/NEJM200104053441406

14. Walport MJ. Complement. Second of two parts. N Engl J Med. 2001;344(15):1140-1144. doi:10.1056/NEJM200104123441506

15. Caine JA, Lin YP, Kessler JR, Sato H, Leong JM, Coburn J. Borrelia burgdorferi Outer Surface Protein C (OspC) Binds Complement Component C4b and Confers Bloodstream 
Survival [published correction appears in Cell Microbiol. 2021 Jan;23(1):e13286]. Cell Microbiol. 2017;19(12):10.1111/cmi.12786. doi:10.1111/cmi.12786

16. Kraiczy P, Hellwage J, Skerka C, et al. Complement resistance of Borrelia burgdorferi correlates with the expression of BbCRASP-1, a novel linear plasmid-encoded surface protein that interacts with human factor $\mathrm{H}$ and FHL-1 and is unrelated to Erp proteins. $J$ Biol Chem. 2004;279(4):2421-2429. doi:10.1074/jbc.M308343200

17. Hartmann K, Corvey C, Skerka C, et al. Functional characterization of BbCRASP-2, a distinct outer membrane protein of Borrelia burgdorferi that binds host complement regulators factor H and FHL-1. Mol Microbiol. 2006;61(5):1220-1236. doi:10.1111/j.1365-2958.2006.05318.x

18. Stevenson B, Tilly K, Rosa PA. A family of genes located on four separate 32-kilobase circular plasmids in Borrelia burgdorferi B31. J Bacteriol. 1996;178(12):3508-3516. doi:10.1128/jb.178.12.3508-3516.1996

19. Stevenson B, El-Hage N, Hines MA, Miller JC, Babb K. Differential binding of host complement inhibitor factor $\mathrm{H}$ by Borrelia burgdorferi Erp surface proteins: a possible mechanism underlying the expansive host range of Lyme disease spirochetes. Infect Immun. 2002;70(2):491-497. doi:10.1128/IAI.70.2.491-497.2002

20. McDowell JV, Wolfgang J, Tran E, Metts MS, Hamilton D, Marconi RT. Comprehensive analysis of the factor $\mathrm{h}$ binding capabilities of Borrelia species associated with lyme disease: delineation of two distinct classes of factor $\mathrm{H}$ binding proteins. Infect Immun. 2003;71(6):3597-3602. doi:10.1128/IAI.71.6.3597-3602.2003

21. McDowell JV, Hovis KM, Zhang H, Tran E, Lankford J, Marconi RT. Evidence that the BBA68 protein (BbCRASP-1) of the Lyme disease spirochetes does not contribute to factor H-mediated immune evasion in humans and other animals. Infect Immun. 2006;74(5):3030-3034.

22. Bykowski T, Woodman ME, Cooley AE, et al. Borrelia burgdorferi complement regulator-acquiring surface proteins (BbCRASPs): Expression patterns during the mammal-tick infection cycle. Int J Med Microbiol. 2008;298 Suppl 1(Suppl 1):249-256. doi:10.1016/j.ijmm.2007.10.002

23. Kenedy MR, Vuppala SR, Siegel C, Kraiczy P, Akins DR. CspA-mediated binding of human factor $\mathrm{H}$ inhibits complement deposition and confers serum resistance in Borrelia burgdorferi. Infect Immun. 2009;77(7):2773-2782. doi:10.1128/IAI.00318-09

24. Rogers EA, Abdunnur SV, McDowell JV, Marconi RT. Comparative analysis of the properties and ligand binding characteristics of $\mathrm{CspZ}$, a factor $\mathrm{H}$ binding protein, derived from Borrelia burgdorferi isolates of human origin. Infect Immun. 2009;77(10):43964405. doi:10.1128/IAI.00393-09

25. Kenedy MR, Akins DR. The OspE-related proteins inhibit complement deposition and enhance serum resistance of Borrelia burgdorferi, the lyme disease spirochete. Infect Immun. 2011;79(4):1451-1457. doi:10.1128/IAI.01274-10

26. Marcinkiewicz AL, Dupuis AP 2nd, Zamba-Campero M, et al. Blood treatment of Lyme 
borreliae demonstrates the mechanism of CspZ-mediated complement evasion to promote systemic infection in vertebrate hosts. Cell Microbiol. 2019;21(2):e12998. doi:10.1111/cmi.12998

27. Hart T, Nguyen NTT, Nowak NA, et al. Polymorphic factor H-binding activity of CspA protects Lyme borreliae from the host complement in feeding ticks to facilitate tick-tohost transmission. PLoS Pathog. 2018;14(5):e1007106. Published 2018 May 29. doi:10.1371/journal.ppat.1007106

28. Garcia BL, Zhi H, Wager B, Höök M, Skare JT. Borrelia burgdorferi BBK32 Inhibits the Classical Pathway by Blocking Activation of the C1 Complement Complex. PLoS Pathog. 2016;12(1):e1005404. Published 2016 Jan 25. doi:10.1371/journal.ppat.1005404

29. Xie J, Zhi H, Garrigues RJ, Keightley A, Garcia BL, Skare JT. Structural determination of the complement inhibitory domain of Borrelia burgdorferi BBK32 provides insight into classical pathway complement evasion by Lyme disease spirochetes. PLoS Pathog. 2019;15(3):e1007659. Published 2019 Mar 21. doi:10.1371/journal.ppat.1007659

30. Margos G, Hepner S, Mang C, et al. Lost in plasmids: next generation sequencing and the complex genome of the tick-borne pathogen Borrelia burgdorferi. BMC Genomics. 2017;18(1):422. Published 2017 May 30. doi:10.1186/s12864-017-3804-5

31. Lin T, Gao L, Zhang C, et al. Analysis of an ordered, comprehensive STM mutant library in infectious Borrelia burgdorferi: insights into the genes required for mouse infectivity. PLoS One. 2012;7(10):e47532. doi:10.1371/journal.pone.0047532

32. Lin YP, Bhowmick R, Coburn J, Leong JM. Host cell heparan sulfate glycosaminoglycans are ligands for OspF-related proteins of the Lyme disease spirochete. Cell Microbiol. 2015;17(10):1464-1476. doi:10.1111/cmi.12448

33. Yang X, Lin YP, Heselpoth RD, et al. Middle region of the Borrelia burgdorferi surfacelocated protein 1 (Lmp1) interacts with host chondroitin-6-sulfate and independently facilitates infection. Cell Microbiol. 2016;18(1):97-110. doi:10.1111/cmi.12487

34. Probert WS, Johnson BJ. Identification of a $47 \mathrm{kDa}$ fibronectin-binding protein expressed by Borrelia burgdorferi isolate B31. Mol Microbiol. 1998;30(5):1003-1015. doi:10.1046/j.1365-2958.1998.01127.x

35. Probert WS, Kim JH, Höök M, Johnson BJ. Mapping the ligand-binding region of Borrelia burgdorferi fibronectin-binding protein BBK32. Infect Immun. 2001;69(6):41294133. doi:10.1128/IAI.69.6.4129-4133.2001

36. Kim JH, Singvall J, Schwarz-Linek U, Johnson BJ, Potts JR, Höök M. BBK32, a fibronectin binding MSCRAMM from Borrelia burgdorferi, contains a disordered region that undergoes a conformational change on ligand binding. J Biol Chem. 2004;279(40):41706-41714. doi:10.1074/jbc.M401691200

37. Brissette CA, Bykowski T, Cooley AE, Bowman A, Stevenson B. Borrelia burgdorferi RevA antigen binds host fibronectin. Infect Immun. 2009;77(7):2802-2812. doi:10.1128/IAI.00227-09

38. Floden AM, Gonzalez T, Gaultney RA, Brissette CA. Evaluation of RevA, a fibronectin- 
binding protein of Borrelia burgdorferi, as a potential vaccine candidate for lyme disease. Clin Vaccine Immunol. 2013;20(6):892-899. doi:10.1128/CVI.00758-12

39. Marconi RT, Sung SY, Hughes CA, Carlyon JA. Molecular and evolutionary analyses of a variable series of genes in Borrelia burgdorferi that are related to $o s p E$ and $o s p F$, constitute a gene family, and share a common upstream homology box. J Bacteriol. 1996;178(19):5615-5626. doi:10.1128/jb.178.19.5615-5626.1996

40. Stevenson B, Bono JL, Schwan TG, Rosa P. Borrelia burgdorferi Erp proteins are immunogenic in mammals infected by tick bite, and their synthesis is inducible in cultured bacteria. Infect Immun. 1998;66(6):2648-2654. doi:10.1128/IAI.66.6.2648-2654.1998

41. Brissette CA, Cooley AE, Burns LH, et al. Lyme borreliosis spirochete Erp proteins, their known host ligands, and potential roles in mammalian infection. Int J Med Microbiol. 2008;298 Suppl 1(Suppl 1):257-267. doi:10.1016/j.ijmm.2007.09.004

42. Akins DR, Caimano MJ, Yang X, Cerna F, Norgard MV, Radolf JD. Molecular and evolutionary analysis of Borrelia burgdorferi 297 circular plasmid-encoded lipoproteins with OspE- and OspF-like leader peptides. Infect Immun. 1999;67(3):1526-1532. doi:10.1128/IAI.67.3.1526-1532.1999

43. Grimm D, Tilly K, Byram R, et al. Outer-surface protein C of the Lyme disease spirochete: a protein induced in ticks for infection of mammals. Proc Natl Acad Sci US A. 2004;101(9):3142-3147. doi:10.1073/pnas.0306845101

44. Tilly K, Krum JG, Bestor A, et al. Borrelia burgdorferi OspC protein required exclusively in a crucial early stage of mammalian infection. Infect Immun. 2006;74(6):3554-3564. doi:10.1128/IAI.01950-05

45. Tilly K, Bestor A, Jewett MW, Rosa P. Rapid clearance of Lyme disease spirochetes lacking OspC from skin. Infect Immun. 2007;75(3):1517-1519. doi:10.1128/IAI.01725-06

46. Hyde JA, Weening EH, Chang M, et al. Bioluminescent imaging of Borrelia burgdorferi in vivo demonstrates that the fibronectin-binding protein BBK32 is required for optimal infectivity. Mol Microbiol. 2011;82(1):99-113. doi:10.1111/j.1365-2958.2011.07801.x

47. Seshu J, Esteve-Gassent MD, Labandeira-Rey M, et al. Inactivation of the fibronectinbinding adhesin gene bbk32 significantly attenuates the infectivity potential of Borrelia burgdorferi. Mol Microbiol. 2006;59(5):1591-1601. doi:10.1111/j.13652958.2005.05042.x

48. Mühleip JJ, Lin YP, Kraiczy P. Further Insights Into the Interaction of Human and Animal Complement Regulator Factor H With Viable Lyme Disease Spirochetes. Front Vet Sci. 2019;5:346. Published 2019 Jan 31. doi:10.3389/fvets.2018.00346

49. R. J. Garrigues, A. D. P. Pierce, M. Hammel, J. T. Skare, B. L. Garcia, A structural basis for inhibition of the complement initiator protease $\mathrm{C} 1 \mathrm{r}$ by Lyme disease spirochetes. bioRxiv, 2021.01.21.427683 (2021).

50. Belperron AA, Bockenstedt LK. Natural antibody affects survival of the spirochete Borrelia burgdorferi within feeding ticks. Infect Immun. 2001;69(10):6456-6462. doi:10.1128/IAI.69.10.6456-6462.2001 
51. Coburn J, Magoun L, Bodary SC, Leong JM. Integrins alpha(v)beta3 and alpha5beta1 mediate attachment of lyme disease spirochetes to human cells. Infect Immun. 1998;66(5):1946-1952. doi:10.1128/IAI.66.5.1946-1952.1998

52. Lin YP, Chen Q, Ritchie JA, et al. Glycosaminoglycan binding by Borrelia burgdorferi adhesin BBK32 specifically and uniquely promotes joint colonization. Cell Microbiol. 2015;17(6):860-875. doi:10.1111/cmi.12407

53. Wu Y, Li Q, Chen XZ. Detecting protein-protein interactions by Far western blotting. Nat Protoc. 2007;2(12):3278-3284. doi:10.1038/nprot.2007.459

54. Nilsson UR, Nilsson B. Simplified assays of hemolytic activity of the classical and alternative complement pathways. J Immunol Methods. 1984;72(1):49-59. doi:10.1016/0022-1759(84)90432-0

55. Roos A, Bouwman LH, Munoz J, et al. Functional characterization of the lectin pathway of complement in human serum. Mol Immunol. 2003;39(11):655-668. doi:10.1016/s01615890(02)00254-7

56. Kardos J, Gál P, Szilágyi L, et al. The role of the individual domains in the structure and function of the catalytic region of a modular serine protease, C1r. J Immunol. 2001;167(9):5202-5208. doi:10.4049/jimmunol.167.9.5202

57. Brisson D, Drecktrah D, Eggers CH, Samuels DS. Genetics of Borrelia burgdorferi. Annu Rev Genet. 2012;46:515-536. doi:10.1146/annurev-genet-011112-112140

58. Setubal JC, Reis M, Matsunaga J, Haake DA. Lipoprotein computational prediction in spirochaetal genomes. Microbiology (Reading). 2006;152(Pt 1):113-121.

doi:10.1099/mic.0.28317-0

59. Zipfel PF, Skerka C. Complement regulators and inhibitory proteins. Nat Rev Immunol. 2009;9(10):729-740. doi:10.1038/nri2620

60. Plummer JS, Cai C, Hays SJ, et al. Benzenesulfonamide derivatives of 2-substituted 4H3,1-benzoxazin-4-ones and benzthiazin-4-ones as inhibitors of complement $\mathrm{C} 1 \mathrm{r}$ protease. Bioorg Med Chem Lett. 1999;9(6):815-820. doi:10.1016/s0960-894x(99)000955

61. Kochi SK, Johnson RC. Role of immunoglobulin G in killing of Borrelia burgdorferi by the classical complement pathway. Infect Immun. 1988;56(2):314-321. doi:10.1128/iai.56.2.314-321.1988

62. Tufts DM, Hart TM, Chen GF, Kolokotronis SO, Diuk-Wasser MA, Lin YP. Outer surface protein polymorphisms linked to host-spirochete association in Lyme borreliae. Mol Microbiol. 2019;111(4):868-882. doi:10.1111/mmi.14209

63. Ripoche J, Erdei A, Gilbert D, Al Salihi A, Sim RB, Fontaine M. Two populations of complement factor $\mathrm{H}$ differ in their ability to bind to cell surfaces. Biochem J. 1988;253(2):475-480. doi:10.1042/bj2530475

64. Ripoche J, Day AJ, Harris TJ, Sim RB. The complete amino acid sequence of human complement factor H. Biochem J. 1988;249(2):593-602. doi:10.1042/bj2490593 
65. Hart T, Yang X, Pal U, Lin YP. Identification of Lyme borreliae proteins promoting vertebrate host blood-specific spirochete survival in Ixodes scapularis nymphs using artificial feeding chambers. Ticks Tick Borne Dis. 2018;9(5):1057-1063. doi:10.1016/j.ttbdis.2018.03.033

66. Hart TM, Dupuis AP 2nd, Tufts DM, et al. Host tropism determination by convergent evolution of immunological evasion in the Lyme disease system. PLoS Pathog. 2021;17(7):e1009801. Published 2021 Jul 29. doi:10.1371/journal.ppat.1009801

67. Dower WJ, Miller JF, Ragsdale CW. High efficiency transformation of E. coli by high voltage electroporation. Nucleic Acids Res. 1988;16(13):6127-6145.

doi:10.1093/nar/16.13.6127

68. Barbour AG. Isolation and cultivation of Lyme disease spirochetes. Yale J Biol Med. 1984;57(4):521-525.

69. Pinne M, Matsunaga J, Haake DA. Leptospiral outer membrane protein microarray, a novel approach to identification of host ligand-binding proteins. $J$ Bacteriol.

2012;194(22):6074-6087. doi:10.1128/JB.01119-12

70. Wilson MM, Bernstein HD. Surface-Exposed Lipoproteins: An Emerging Secretion Phenomenon in Gram-Negative Bacteria. Trends Microbiol. 2016;24(3):198-208. doi:10.1016/j.tim.2015.11.006

71. Dulipati V, Meri S, Panelius J. Complement evasion strategies of Borrelia burgdorferi sensu lato. FEBS Lett. 2020;594(16):2645-2656. doi:10.1002/1873-3468.13894

72. Siegel C, Schreiber J, Haupt K, et al. Deciphering the ligand-binding sites in the Borrelia burgdorferi complement regulator-acquiring surface protein 2 required for interactions with the human immune regulators factor $\mathrm{H}$ and factor $\mathrm{H}$-like protein 1. J Biol Chem. 2008;283(50):34855-34863. doi:10.1074/jbc.M805844200

73. Hartmann K, Corvey C, Skerka C, et al. Functional characterization of BbCRASP-2, a distinct outer membrane protein of Borrelia burgdorferi that binds host complement regulators factor H and FHL-1. Mol Microbiol. 2006;61(5):1220-1236. doi:10.1111/j.1365-2958.2006.05318.x

74. Radolf JD, Kumar S. The Treponema pallidum Outer Membrane. Curr Top Microbiol Immunol. 2018;415:1-38. doi:10.1007/82_2017_44

75. Pinne M, Haake DA. LipL32 Is a Subsurface Lipoprotein of Leptospira interrogans: presentation of new data and reevaluation of previous studies. PLoS One. 2013;8(1):e51025. doi:10.1371/journal.pone.0051025 
76. Haake DA, Matsunaga J. Leptospiral Immunoglobulin-Like Domain Proteins: Roles in Virulence and Immunity. Front Immunol. 2021;11:579907. Published 2021 Jan 8. doi:10.3389/fimmu.2020.579907

77. Cox DL, Luthra A, Dunham-Ems S, et al. Surface immunolabeling and consensus computational framework to identify candidate rare outer membrane proteins of Treponema pallidum. Infect Immun. 2010;78(12):5178-5194. doi:10.1128/IAI.00834-10

78. Bykowski T, Woodman ME, Cooley AE, et al. Coordinated expression of Borrelia burgdorferi complement regulator-acquiring surface proteins during the Lyme disease spirochete's mammal-tick infection cycle. Infect Immun. 2007;75(9):4227-4236. doi:10.1128/IAI.00604-07

79. Farady CJ, Craik CS. Mechanisms of macromolecular protease inhibitors. Chembiochem. 2010;11(17):2341-2346. doi:10.1002/cbic.201000442

80. Nagy ZA, Szakács D, Boros E, et al. Ecotin, a microbial inhibitor of serine proteases, blocks multiple complement dependent and independent microbicidal activities of human serum. PLoS Pathog. 2019;15(12):e1008232. Published 2019 Dec 20.

doi:10.1371/journal.ppat.1008232

81. Lin YP, Diuk-Wasser MA, Stevenson B, Kraiczy P. Complement Evasion Contributes to Lyme Borreliae-Host Associations. Trends Parasitol. 2020;36(7):634-645. doi:10.1016/j.pt.2020.04.011

82. Takacs CN, Scott M, Chang Y, et al. A CRISPR interference platform for selective downregulation of gene expression in Borrelia burgdorferi [published online ahead of print, 2020 Nov 30]. Appl Environ Microbiol. 2020;87(4):e02519-20. doi:10.1128/AEM.02519-20

83. Stevenson B, Tilly K, Rosa PA. A family of genes located on four separate 32-kilobase circular plasmids in Borrelia burgdorferi B31. J Bacteriol. 1996;178(12):3508-3516. doi:10.1128/jb.178.12.3508-3516.1996

84. Metts MS, McDowell JV, Theisen M, Hansen PR, Marconi RT. Analysis of the OspE determinants involved in binding of factor $\mathrm{H}$ and OspE-targeting antibodies elicited during Borrelia burgdorferi infection in mice. Infect Immun. 2003;71(6):3587-3596. doi:10.1128/IAI.71.6.3587-3596.2003

85. Miller JC, El-Hage N, Babb K, Stevenson B. Borrelia burgdorferi B31 Erp proteins that are dominant immunoblot antigens of animals infected with isolate $\mathrm{B} 31$ are recognized by only a subset of human lyme disease patient sera. J Clin Microbiol. 2000;38(4):15691574. 
1014

1015

1016

1017

1018

1019

1020

1021

1022

1023

1024

1025

1026

1027

1028

1029

1030

1031

1032

1033

1034
86. Babb K, McAlister JD, Miller JC, Stevenson B. Molecular characterization of Borrelia burgdorferi erp promoter/operator elements. J Bacteriol. 2004;186(9):2745-2756.

doi:10.1128/JB.186.9.2745-2756.2004

87. Kraiczy P, Hellwage J, Skerka C, et al. Immune evasion of Borrelia burgdorferi: mapping of a complement-inhibitor factor H-binding site of BbCRASP-3, a novel member of the Erp protein family. Eur J Immunol. 2003;33(3):697-707.

doi:10.1002/eji.200323571

88. Siegel C, Hallström T, Skerka C, et al. Complement factor H-related proteins CFHR2 and CFHR5 represent novel ligands for the infection-associated CRASP proteins of Borrelia burgdorferi. PLoS One. 2010;5(10):e13519. Published 2010 Oct 20.

doi:10.1371/journal.pone.0013519

89. Hellwage J, Meri T, Heikkilä T, et al. The complement regulator factor $\mathrm{H}$ binds to the surface protein OspE of Borrelia burgdorferi. J Biol Chem. 2001;276(11):8427-8435. doi:10.1074/jbc.M007994200

90. Alitalo A, Meri T, Comstedt P, et al. Expression of complement factor $\mathrm{H}$ binding immunoevasion proteins in Borrelia garinii isolated from patients with neuroborreliosis. Eur J Immunol. 2005;35(10):3043-3053. doi:10.1002/eji.200526354

91. McDowell JV, Wolfgang J, Senty L, Sundy CM, Noto MJ, Marconi RT. Demonstration of the involvement of outer surface protein E coiled coil structural domains and higher order structural elements in the binding of infection-induced antibody and the complement-regulatory protein, factor H. J Immunol. 2004;173(12):7471-7480. doi:10.4049/jimmunol.173.12.7471 


\section{Figures and Tables}

Figure 1. Screening the $B$. burgdorferi surface lipoproteome identifies high affinity interactions between ErpB and ErpQ with human C1. (A) $1 \times 10^{6}$ strain B31-e2 producing one of 80 B. burgdorferi surface lipoproteins ((6); Table S1), as well as a periplasmic lipoprotein (BB0460) to serve as a negative control, were applied to microtiter wells coated with human C1 complex in duplicate. After washing, bound bacteria were quantitated by the change in $\mathrm{OD}_{405 \mathrm{~nm}}$ over time by ELISA using an anti- $B b$ antibody (Abcam, ab20118). The clones are sorted in order 1042 of binding signal. Error bars indicate SEM. (A, inset) Binding of clones producing the indicated B. burgdorferi Elp protein, along with a positive control (BBK32) or a periplasmic negative control (BB0460), to immobilized human C1 complex or BSA was quantitated as described above. Error bars indicate SEM. ****, $\mathrm{p}<0.0001$; *, $\mathrm{p}<0.05$; ns, not significant using Student's $t$ test to compare mean values. (B) Binding of the indicated GST-fusion proteins to wells coated

1047 with the indicated concentration of human C1 complex was quantitated. The experiment was 1048 performed six times (GST-ErpB) or nine times (GST-BBK32 and GST-ErpQ) at each 1049 concentration and error bars indicate SEM. Affinity analysis was performed with Prism 1050 GraphPad software, using a non-linear regression analysis. (C) The ability for GST-ErpB (left) 1051 GST-ErpQ (right) to bind human C1 complex was evaluated by SPR. A two-fold dilution series 1052 (0.6 - $150 \mathrm{nM})$ of C1 complex was injected over GST-ErpB and GST-ErpQ biosensors and 1053 steady-state affinity analysis was carried out with T200 Evaluation Software. Each SPR 1054 experiment was performed in triplicate. Equilibrium dissociation constants $\left(K_{\mathrm{D}}\right)$ calculated from 
1057 Figure 2. ErpB and ErpQ preferentially bind activated forms of C1r and C1s.

1058 A) Extracts from untreated (“"“) or pronase-treated (“+”) $1 \times 10^{7}$ strain B31-e2 spirochetes that 1059 ectopically produce the indicated surface lipoproteins were separated by SDS-PAGE and 1060 transferred to PVDF membranes. The filters were probed with purified C1 complex (top), C1r 1061 enzyme (middle) or C1r proenzyme (bottom), and bound probe revealed by anti-C1r antibody, 1062 followed by HRP-conjugated anti-mouse antibody. Shown is a representative of 3 experiments. 1063 B) Filters prepared identically to panel A were probed with purified C1 complex (top), C1s 1064 enzyme (middle) or C1s proenzyme (bottom), and bound probe revealed by anti-C1s antibody, 1065 followed by HRP-conjugated anti-mouse antibody. Shown is a representative of 3 experiments.

1066 C and D) Biosensors immobilized with GST-ErpB (top) or GST-ErpQ (bottom) were tested by 1067 SPR for binding to the indicated concentrations of the enzyme or proenzyme forms of C1r (C) or 1068 C1s (D) Injection series were each performed in triplicate. For both panels C) and D), steady1069 state affinity fits were determined by T200 Biacore Evaluation software and $K_{\mathrm{D}}$ values are 1070 reported in Table 1.

1071 
1072 Figure 3. ErpQ is an allosteric inhibitor of complement C1s. A) Enzymatic cleavage by C1s

1073 of the small peptide substrate Z-L-Lys-sBzl was assayed with DTNB (Ellman's reagent) in the 1074 presence of $25 \mu \mathrm{M}$ BBK32-C (non-inhibitory control) or ErpQ at $25^{\circ} \mathrm{C}$ for $1 \mathrm{hr}$. Experiments 1075 were performed in triplicate. Absorbance was read at $412 \mathrm{~nm}$ and signals were normalized to 1076 negative control no-substrate wells. B) Top: Proteolytic cleavage of C2 by C1s enzyme produces $1077 \sim 70 \mathrm{kDa} \mathrm{C} 2 \mathrm{~b}$ and $\sim 35 \mathrm{kDa} \mathrm{C} 2 \mathrm{a}$ after $1 \mathrm{hr}$ at $37^{\circ} \mathrm{C}$. Lanes $1-5$ : $\mathrm{C} 2 \mathrm{~b}$ accumulation in the presence 1078 (“+”) or absence (““-“) or $25 \mu \mathrm{M}$ ErpQ, $25 \mu \mathrm{M}$ BBK32-C (non-inhibitory control), $6.25 \mathrm{nM} \mathrm{C1s,}$ 1079 and $685 \mathrm{nM} \mathrm{C} 2$. (Note that the amount of $\mathrm{C} 1 \mathrm{~s}$ loaded is below the level of detection by SDS1080 PAGE). Lanes 6-13: C2b accumulation in the presence of $6.25 \mathrm{nM} \mathrm{C1s,} 685 \mathrm{nM} \mathrm{C2}$ and a two1081 fold dilution series (from 16 to $0.13 \mu \mathrm{M}$ ) of ErpQ. Bottom: The fraction of C2b relative to total 1082 input $\mathrm{C} 2$ in the same lane determined by densitometry analysis data are normalized to C2 (lane 1083 5) and C1s digested C2 (lane 6). A representative gel is shown. The experiment was performed

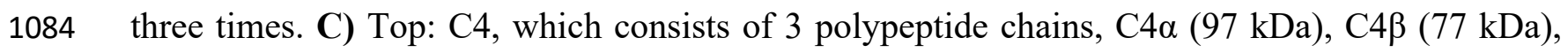
$1085 \mathrm{C} 4 \gamma(33 \mathrm{kDa})$, is cleaved by $\mathrm{C} 1 \mathrm{~s}$ enzyme for $1 \mathrm{hr}$ at $37^{\circ} \mathrm{C}$ to produce $\mathrm{C} 4 \alpha^{\prime}(88 \mathrm{kDa})$. Lanes $1-5$ : 1086 SDS-PAGE profile in the presence (“+”) or absence (“-“) or $25 \mu \mathrm{M}$ ErpQ, $25 \mu \mathrm{M}$ BBK32-C 1087 (non-inhibitory control), $6.25 \mathrm{nM} \mathrm{C1s}$, and $616 \mathrm{nM} \mathrm{C4}$. Lanes 6-13: SDS-PAGE profile in the 1088 presence of $6.25 \mathrm{nM} \mathrm{C1s}, 616 \mathrm{nM} \mathrm{C} 4$ and a two-fold dilution series (from 25 to $0.20 \mu \mathrm{M}$ ) of 1089 ErpQ. Bottom: The fraction of $\mathrm{C} 4 \alpha^{\prime}$ relative to input $\mathrm{C} 4 \beta$ in the same lane and normalized to $\mathrm{C} 1 \mathrm{~s}$ $1090+$ C4 positive control (lane 6) and negative control C4 (lane 5) was determined by densitometry 1091 analysis. 
1093 Figure 4. ErpB and ErpQ inhibit the classical pathway of complement. A-C) Normal human

1094 serum (NHS) was incubated with the indicated concentration of purified GST-fusion proteins, 1095 then added to wells precoated with human IgM. Deposition of A) C4b, B) C3b, or C) C5b-C9

1096 was determined by the addition of the appropriate primary and secondary antibodies (see 1097 Materials and Methods) enumerated by absorbance at $\mathrm{OD}_{405 \mathrm{~nm}}$ or $\mathrm{OD}_{450 \mathrm{~nm}}$. Each well was 1098 normalized to wells with no inhibitor (100\%) and no serum (0\%). Curves were fit using 1099 nonlinear regression to determine $\mathrm{IC}_{50}$ values. D) NHS was incubated with the indicated 1100 concentration of purified GST-fusion proteins and then added to pre-opsonized sheep 1101 erythrocytes (see Materials and Methods). Erythrocyte lysis was determined by $\mathrm{OD}_{405 \mathrm{~nm}}$ and 1102 normalized to lysis by deionized water (100\%) and no serum (0\%). Error bars indicate SEM. 1103 Each concentration was tested a minimum of three times. 
1105 Figure 5. Ectopic production of ErpB and ErpQ protect spirochetes from complement-

1106 mediated killing. $5 \times 10^{7}$ spirochetes were treated with a $4 \mu \mathrm{g} / \mathrm{ml}$ of an $\alpha-B$. burgdorferi strain

1107 B31 mouse polyclonal antibody or its isotype (IgG) control, followed by exposure to $20 \%$

1108 untreated or heat-inactivated NHS (or heat-inactivated NHS) containing $10 \mu \mathrm{g} / \mathrm{ml}$ lysozyme for

1109 four hours. Samples were grown in BSK-II for 72 hours at $33^{\circ} \mathrm{C}$ and enumerated by dark field

1110 microscopy. Survival index was calculated by dividing the culture density of each sample in the

1111 "Bb-specific $\mathrm{Ab}$ " or "Isotype control Ab" groups by the average density of the heat-inactivated

1112 serum group for each strain. Shown is the mean and SEM of triplicate samples. ***, $<<0.001$;

$1113 * *, \mathrm{p}<0.01$; ns, not significant using Student's $t$ test to compare mean values. 


\section{Table 1.}

\begin{tabular}{|c|c|c|c|}
\hline $\begin{array}{c}\text { GST-fusion } \\
\text { protein }\end{array}$ & $\begin{array}{c}\text { Complement } \\
\text { protein }\end{array}$ & $\begin{array}{c}\text { ELISA } \\
K_{\mathbf{D}}(\mathbf{n M})^{\mathrm{a}}\end{array}$ & $\begin{array}{c}\text { SPR } \\
K_{D}(\mathbf{n M})^{b}\end{array}$ \\
\hline \multirow{5}{*}{ GST-ErpB } & $\mathrm{C} 1$ & $3.4 \pm 0.4$ & $5.6 \pm 1.5$ \\
\hline & C1r enzyme & $41 \pm 4.3$ & $100 \pm 27$ \\
\hline & C1s enzyme & $6.7 \pm 0.7$ & $3.9 \pm 0.48$ \\
\hline & C1r proenzyme & $\mathrm{NB}^{\mathrm{c}}$ & NB \\
\hline & C1s proenzyme & NA & $270 \pm 55$ \\
\hline \multirow{5}{*}{ GST-ErpQ } & $\mathrm{C} 1$ & $3.8 \pm 1.2$ & $11 \pm 2.0$ \\
\hline & C1r enzyme & $11 \pm 1.9$ & $97 \pm 35$ \\
\hline & C1s enzyme & $4.7 \pm 1.0$ & $4.5 \pm 1.0$ \\
\hline & C1r proenzyme & NB & NB \\
\hline & C1s proenzyme & NB & $170 \pm 73$ \\
\hline
\end{tabular}

$1117{ }^{\mathrm{a}} \mathrm{K}_{\mathrm{D}}$ determined by quantitative ELISA.

$1118{ }^{\mathrm{b}} \mathrm{K}_{\mathrm{D}}$ determined by SPR.

1119 'NB, no detectable binding. 
1121 Table 2. IC 50 for ErpB- and ErpQ-mediated inhibition of the classical pathway of 1122 complement

1123

\begin{tabular}{|c|c|c|c|c|}
\hline Protein & Hemolysis & C5b-9 & C3b & C4b \\
\hline GST-BBK32 & $79 \pm 5.2$ & $100 \pm 20$ & $29 \pm 1.0$ & $18 \pm 3.3^{*}$ \\
\hline GST-ErpQ & $1500 \pm 240$ & $1000 \pm 210$ & $450 \pm 26$ & $260 \pm 62$ \\
\hline GST-ErpB & $1600 \pm 190$ & $300 \pm 43$ & $570 \pm 29$ & $330 \pm 130$ \\
\hline
\end{tabular}

1124

1125

1126

1127

* $\mathrm{IC}_{50}$ based on non-GST-tagged BBK32-C construct. 


\section{$1128 \quad$ Fig 1}

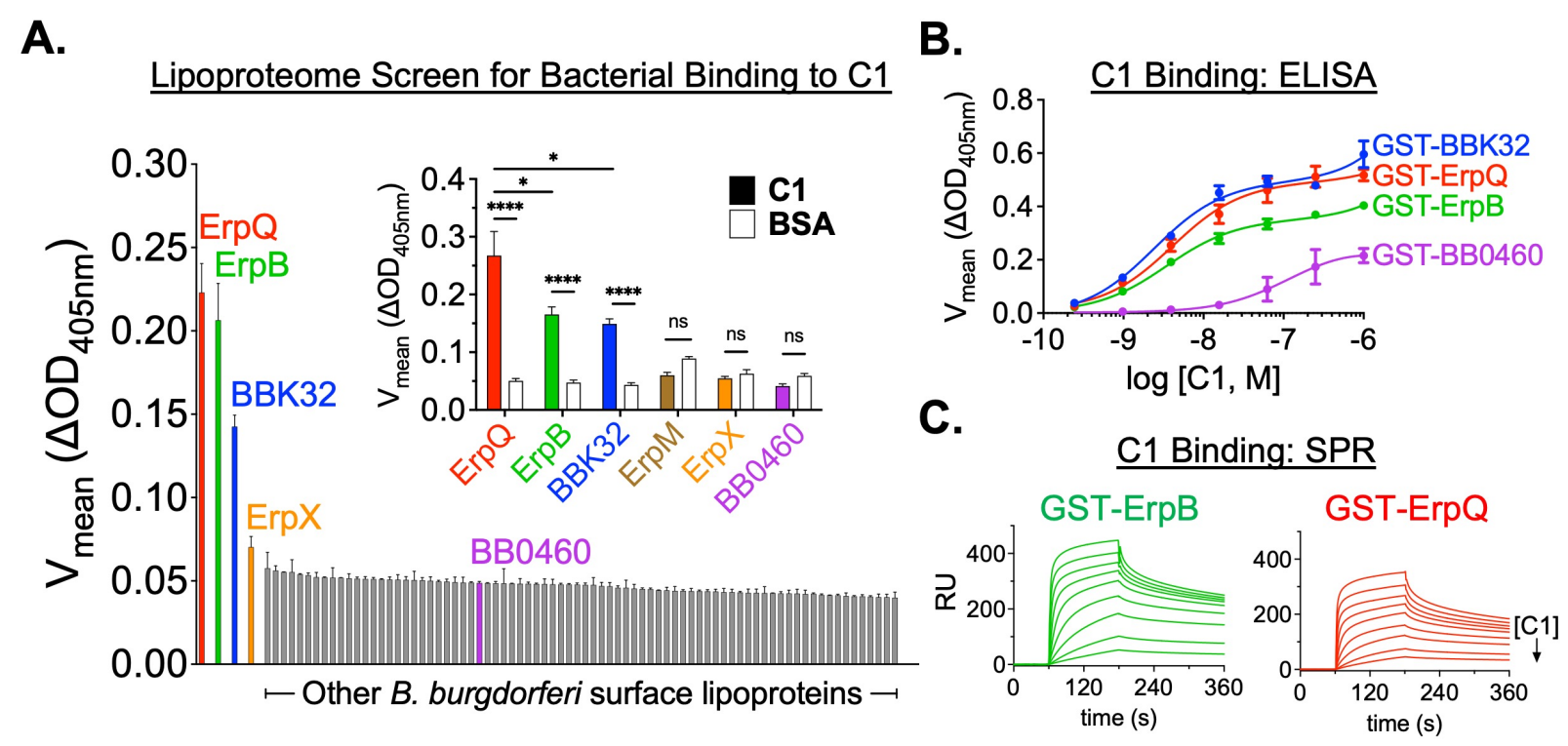

1129

1130

1131 
A.

BBK32 ErpB ErpQ BB0460

Pronase: -+-+-+-+
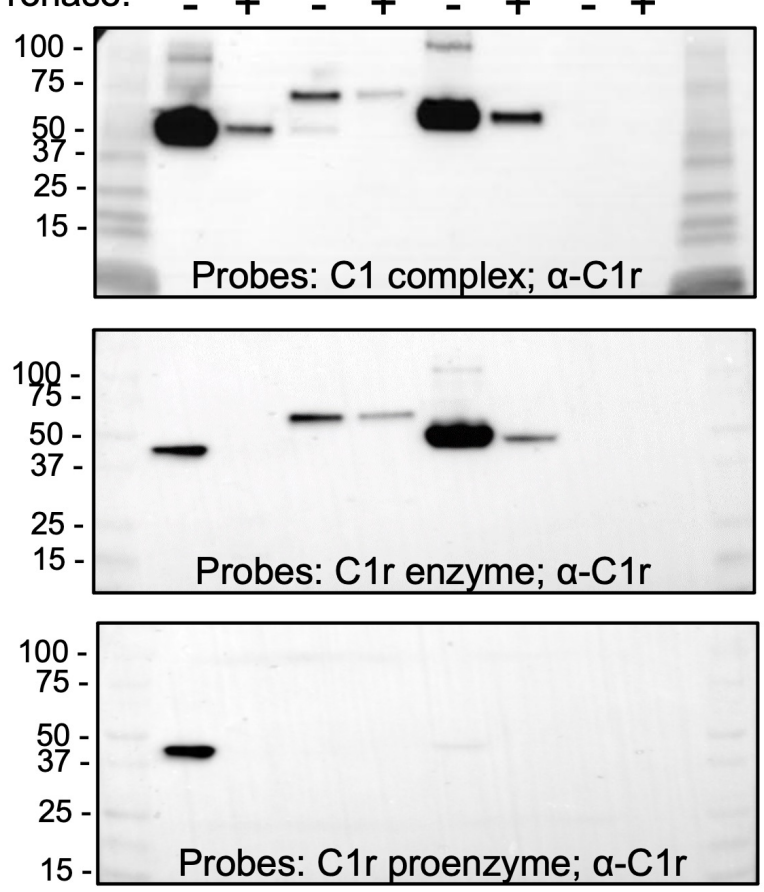

C.

SPR: Steady-state Affinity Fit
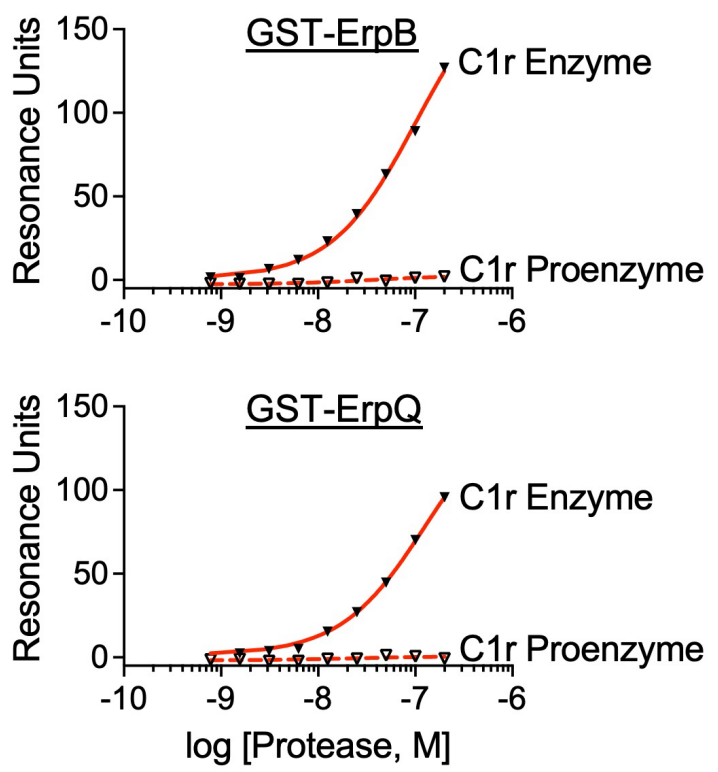

B. BBK32 ErpB ErpQ $\underline{\text { BB0460 }}$ $-+-+-+-+$
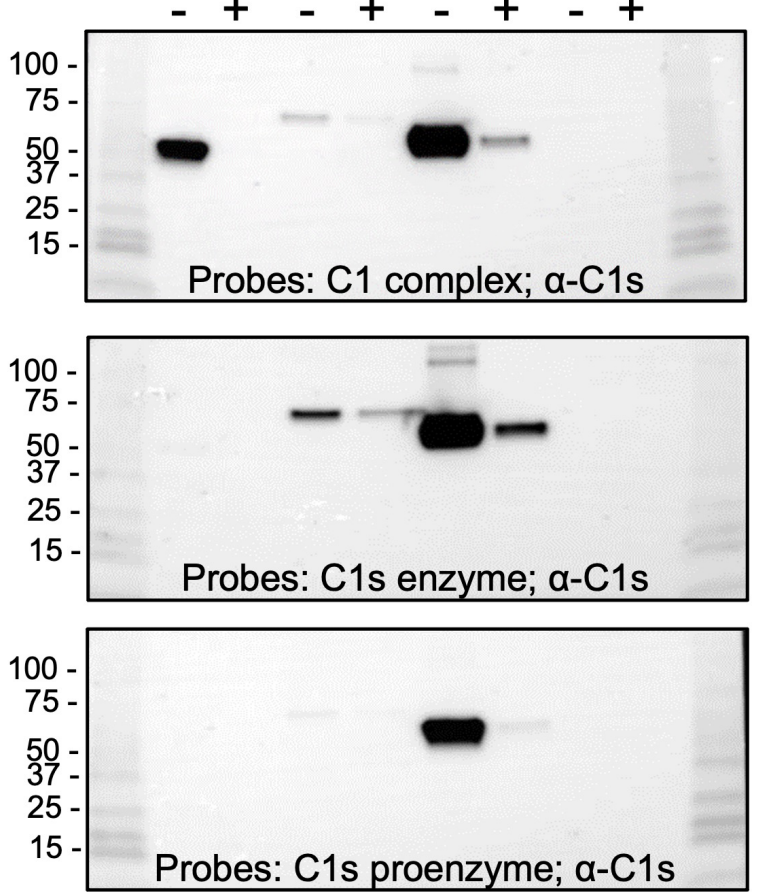

D.

SPR: Steady-state Affinity Fit
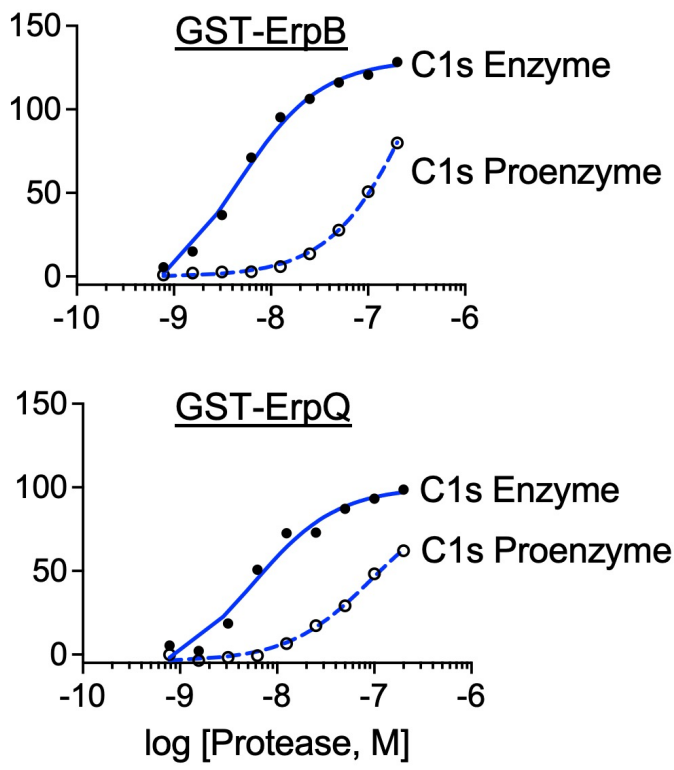
Fig 3

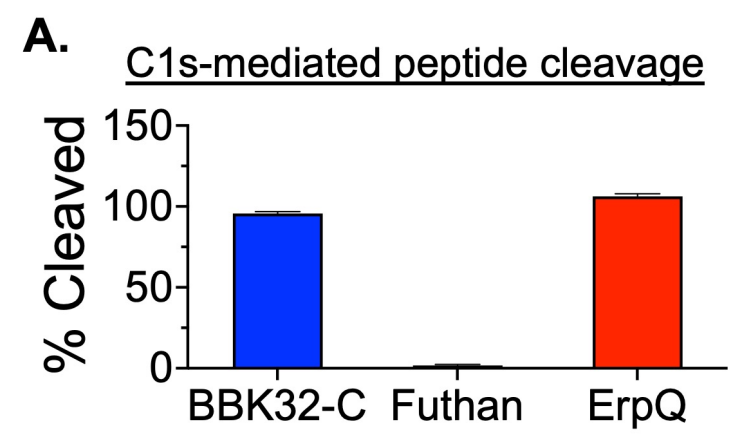

B.

\section{C2 cleavage}

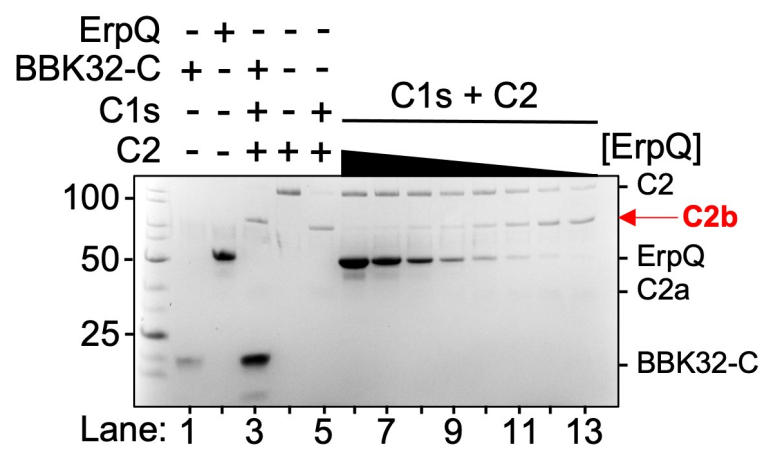

D.

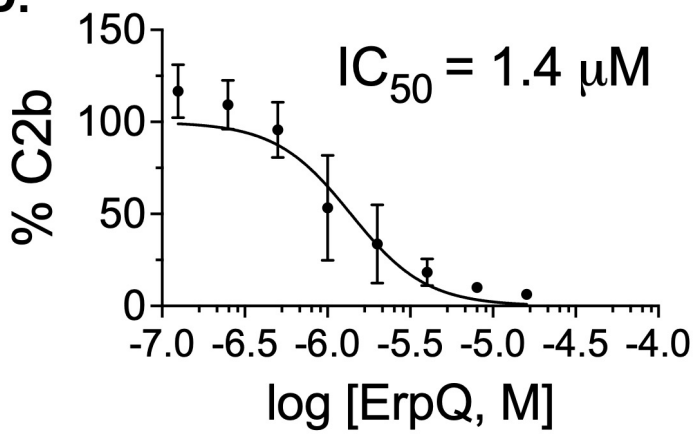

C.

\section{C4 cleavage}

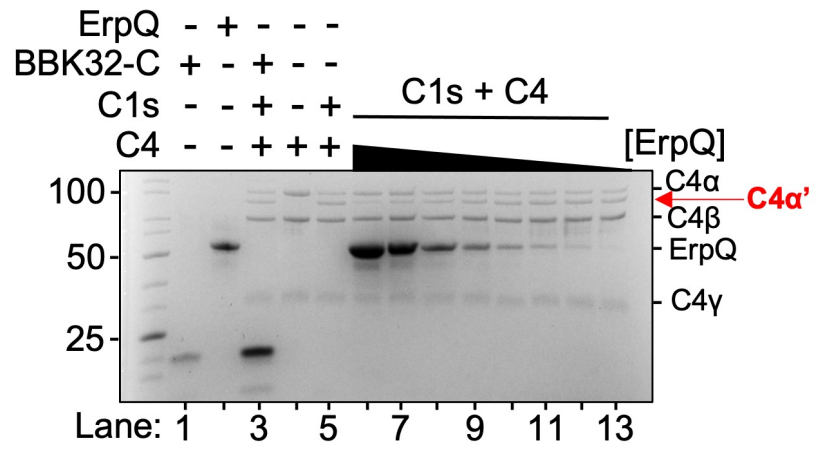

E.

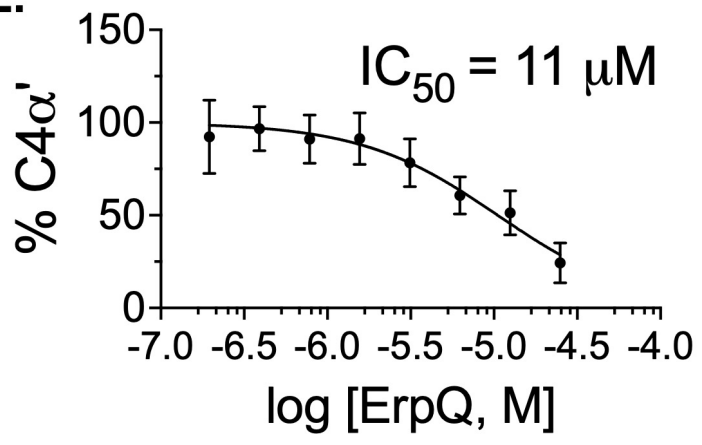




\section{$1141 \quad$ Fig 4}

1142

1143
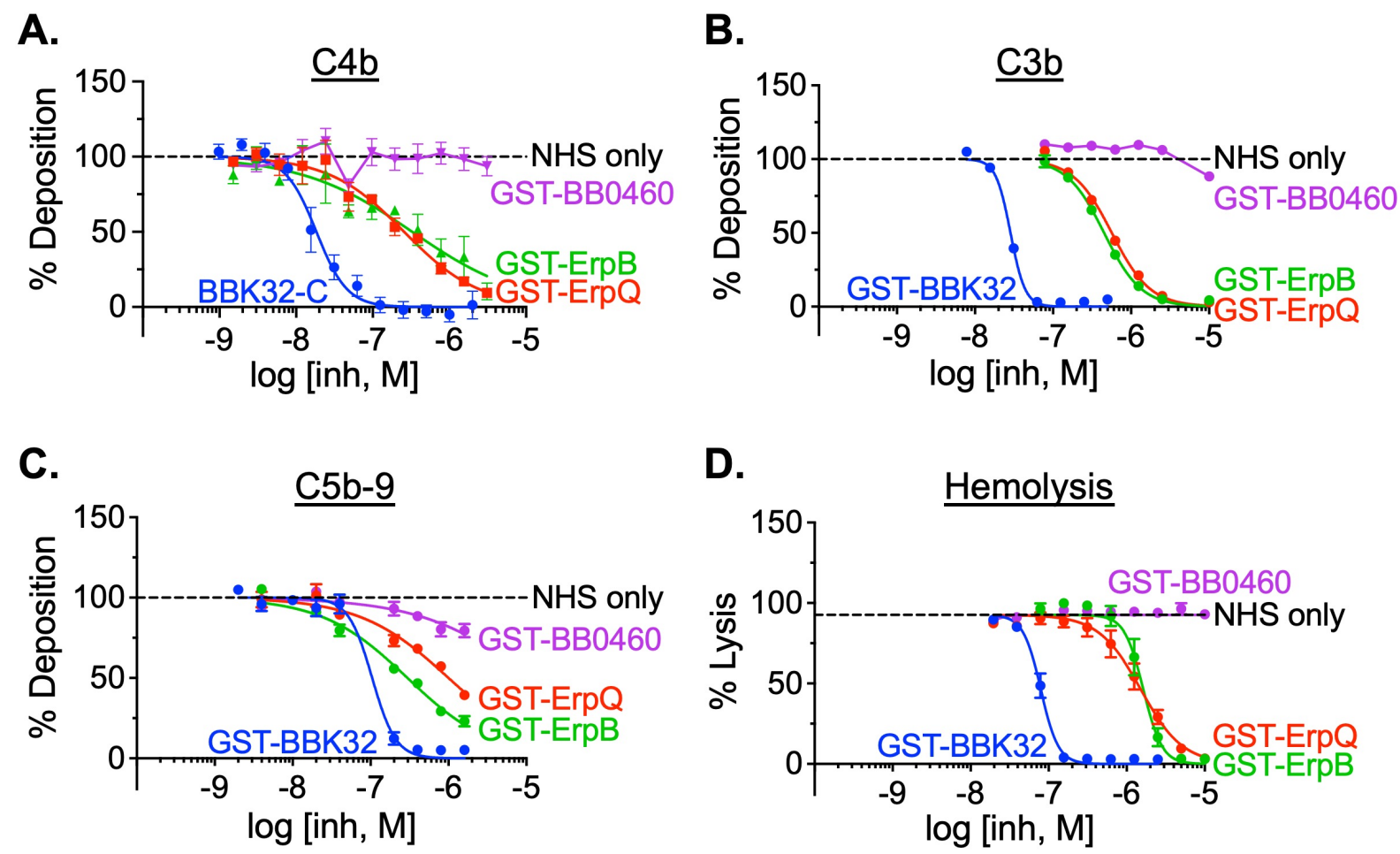


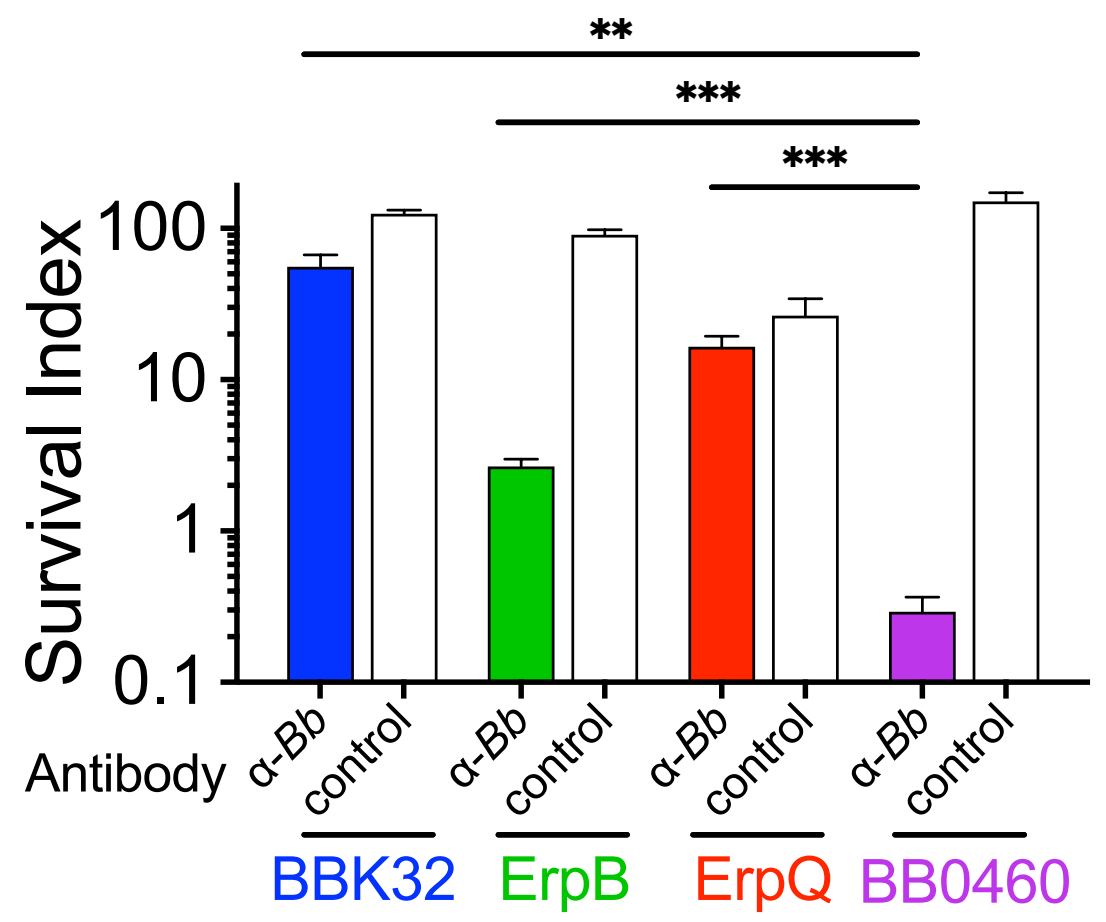

